\title{
Experimental Study on the Novel Interface Bond Behavior between Fiber-Reinforced Concrete and Common Concrete through 3D-DIC
}

\author{
Yujie Yuan $\left(\mathbb{D}\right.$, Ming Li $\mathbb{D}^{D}$, Abduqader S. S. Alquraishi $\mathbb{D}^{D}$, and Hongye Sun \\ Department of Architecture Engineering, Chang'an University, Xi'an, China \\ Correspondence should be addressed to Yujie Yuan; 15029287701@163.com
}

Received 26 August 2021; Revised 28 September 2021; Accepted 29 September 2021; Published 18 October 2021

Academic Editor: Dora Foti

Copyright (c) 2021 Yujie Yuan et al. This is an open access article distributed under the Creative Commons Attribution License, which permits unrestricted use, distribution, and reproduction in any medium, provided the original work is properly cited.

\begin{abstract}
A novel method was proposed to improve the bond behavior of new-to-old concrete interface, which was beneficial to introduce the fiber-reinforced concrete only at the old concrete interface. This study investigated the effect of the fiber addition, strength grade of new concrete, interfacial angle, and surface treatment types on the bond behavior in terms of the new-to-old concrete through the axial tensile tests. The three-dimensional digital image correlation technique (3D-DIC) and scanning electron microscope were adopted to evaluate the variation of specimen surface strain distributions and microstructure of fiber-reinforced concrete and bond interface between new-to-old concrete. The experimental results indicated that interfacial angle and surface treatment type were significantly promoted bond behaviors, while the specimen cooperating with steel fibers had the highest bond strength. Besides, the maximum strain locations obtained from 3D-DIC method were the same as the location of the specimen failure, which indicated the 3D-DIC method can be adopted to forecast the structural failure. The microcrack strain located in the major crack was decreased with the development of the major crack. Ample crystals and $\mathrm{Ca}(\mathrm{OH})^{2}$ were generated in the interface between the new-to-old concrete to weaken the bond strength. Moreover, this paper provided the mechanics-driven and machine learning method to predict the bond strength. This study provides a new interface bonding method for the fabricated and large span structure to effectively avoid cracking of new-to-old concrete.
\end{abstract}

\section{Introduction}

Concrete has received wide application in engineering owing to abundant raw materials and inexpensive prices while offering high compressive strength, strong plasticity, and long durability. However, it is inevitable that a large number of new-to-old concrete interfaces will be formed in the large span and high-rise concrete structures and prefabricated structures due to the difference in concrete pouring time or connection joint of fabricated structure. The new-to-old concrete interface has been commonly recognized as one of the most vulnerable links in the concrete structure [1-8]. Moreover, concrete has the characteristics of low tensile strength and is easy to crack. Nevertheless, concrete structures are generally under compression on normal service conditions, while some structures, such as high-rise buildings, long-span bridges, and subgrade, are under tension subjected to wind and vehicle loading. In such cases, interface cracking has a significant impact on corrosion resistance, which results in concerns about the service lives of these structures. Hence, it is fundamental to investigate the bond behavior of new-to-old concrete interface.

The composition of the new-to-old interfacial bond force is similar to that of the cement-aggregate interface, which is mainly composed of interlocking and chemical forces. Thereinto, the main effect is interlocking force, while the influence of chemical force is relatively small. The interlocking effect refers to the mechanical interaction that when the viscous cement slurry penetrates into the voids on the surface of the old concrete, the new and old concretes interlock and combine with each other after hardening to form a certain bond strength [1,9-15]. In other words, the interlocking effect is formed mainly by the growth of hydration products (ettringite, calcium silicate hydrates, and 
calcium hydroxide crystals) of new concrete in the larger pores and cracks of old concrete. Besides, a water film will be emerged on the old concrete surface during repair mainly attributed to its hydrophilicity. This will result in a generation of ettringite and calcium hydroxide crystals at the interface, thus weakening the interface bonding performance. Hence, the mechanical properties of new-to-old concrete interface are vital to the structural integrity.

Ample researches have been carried out to explore the various effectors affecting the bond behavior of new-to-old concrete interface. Before applicating the overlay, the substrate surfaces of the old concrete must be treated to guarantee a certain roughness at the interface. There are many methods for treating the interfaces, including artificial chiseling [16-22], wire brushing [16, 19, 20, 23], mechanical cutting $[22,24]$, chipping $[10,25]$, high pressure water injection $[22,26]$, sandblasting $[9,10,16,20,23]$, and rectangular strips [25]. After the treatment, the uneven texture on substrate surface makes the interface rougher, thus increasing the contact area with the overlay. Tests carried out by Eduardo et al. [10], Tateh et al. [20,21], Semendary et al. [4], and $\mathrm{Hu}$ et al. [25] reported that those methods have significantly affected the tensile bond behavior of new-to-old concrete interface. Besides, the interfacial agent is another important factor to enhance the tensile strength of the newto-old concrete interface. The common choices of this way mainly include silica fume [27], fly ash [27, 28], cement paste [27, 29-33], epoxy adhesive [3], and polymer binder [20,32,34-37]. Xi et al. [28] and Huang et al. [38] examined the effects of the interfacial agent on the bond performance of new-to-old concrete interface and reported that the interfacial agent could improve the tensile bond strength. There also exists another way to improve the interface bond behavior, which is to enhance the strength grades of the new concrete. The splitting tests performed by Huang et al. [38], Gadri et al. [17], and Sabah et al. [23] revealed that the bond strength increased as the strength grade of the new concrete increased. Shou et al. [26] also investigated the influence of interfacial angle. Zanotti et al. [39, 40] experimentally found that adding fibers to the new concrete substantially increased the bond strength through the slant tests. Based on the aforementioned research, although the bonding performance of the new-to-old concrete interface can be improved by increasing the new concrete strength, interface roughness, using interface agents, and so on, the effects were not significant. It must be admitted that the concrete cooperating with fibers can effectively enhance its tensile properties. Moreover, numerous studies have focused on the interface bonding properties of fiber-reinforced concrete (FRC) as new concrete $[39,40]$, and there is almost no research on FRC as old concrete. However, the large-volume FRC production is a challenge due to the fibers being not easy to be uniformly dispersed in the concrete. As shown in Figure 1(c), it is an excellent choice to adopt only few FRC near the old concrete interface. The implementation of this method is to pour a part of FRC in the interface area after the old concrete is poured. Because the pouring time between the two types of concrete is almost the same time, the formation of new-to-old concrete interface is avoided. After the interface is processed, the fibers are exposed. The exposed fibers facilitate the combination of the new concrete to form an interface area with fibers, as shown in Figure 1(c). This type of interface is suitable for prefabricated structures as gap junctions or structures require multilayer pouring. Hence, this paper employed the fiber-reinforced concrete as the old concrete.

However, the common methods for testing the tensile bond performance of new-to-old concrete interface are splitting [4, 25, 26, 38, 41], axial tension [27], and pull-off tests $[3,23,31,32,42]$. It is an excellent choice employing the splitting tests for researchers, which is mainly attributed to simple test apparatus and is easy to operate while offering stable and reliable test data. Nevertheless, the compressive load is subjected to the upper and lower boundary along with the specimen interface during the test. The tensile strength of concrete specimens will be reduced due to the effect of longitudinal compressive stresses. As for the axial tensile and pull-off tests, the interface of the specimen is directly subjected to tensile loading, while the specimen fabrication for such tests is complicated. Moreover, it is difficult to align specimens in the load direction, and the local failure is likely to occur. The phenomenon is mainly due to the local stress concentration causing by clamp tightly fixed on the specimen, thus introducing a large scatter in the test data. Therefore, only a small part of the experiments adopted axial tensile tests to study the bond properties of the new-to-old interfaces. Herein, in order to directly obtain the axial tensile bond strength of the new-to-old concrete interfaces, this paper was dedicated to designing a variable bond interface specimen to increase the contact area between the specimen and fixture. An adjustable fixture was adopted to fix the specimen to avoid the local stress concentration. Besides, the deformation characteristics of new-to-old concrete surfaces under axial tensile load are rarely investigated, while this part is vital for further study in this field. Hence, the axial tensile experiments were carried out to investigate the effect of the fiber addition, strength grade of new concrete, interfacial angle, and surface treatment type on the bond behavior between the new-to-old concrete in this paper. Meanwhile, the evolutions of the interface damage and creak propagations were monitored by the three-dimensional digital image correlation technique (3D-DIC). Moreover, the microstructures and components of FRC and bond interface were explored by scanning electron microscope observations (SEM).

In fact, there are two typical methods for predicting the new-to-old concrete bond strength, including mechanicsdriven and machine learning methods. Though the mechanics-driven method can better reveal mechanism and behavior interpretation, the formula proposed based on this method usually introduces simplifications and assumptions for better engineering application. Besides, those formulas may be specific to some applicable situations. To address the aforementioned challenges, the machine learning method only utilize fewer influence parameters and takes advantage of numerous accumulated or measured test data for predicting data, while offering high accuracy and robustness $[43,44]$. Hence, this paper employed the machine learning 


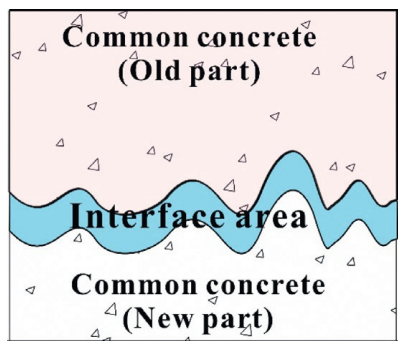

(a)

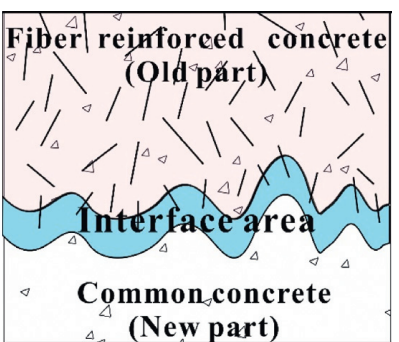

(b)

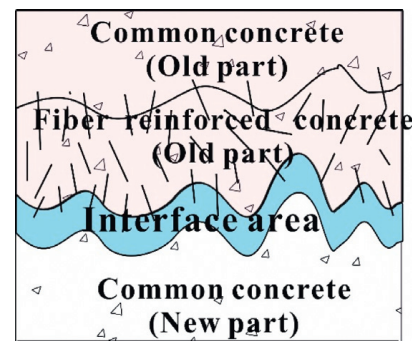

(c)

FIgURE 1: New-to-old concrete.

and mechanics-driven method for calculating the tensile bond strength of new-to-old concrete interface and compared the two methods characteristics for facilitating engineer selection.

\section{Experimental Program}

The effects of the fiber addition, strength grade of new concrete, interfacial angle, and surface treatment type on the bond behavior between the new-to-old concrete interface were investigated through the axial tensile test. All specimens have the same dimensions composed of the old concrete and new concrete. The details of the specimens are shown in Table 1.

2.1. Material Properties. In this paper, common concrete and FRC were mainly composed of ordinary Portland cement (P.O. 42.5), coarse aggregate with a particle size range of $5-20 \mathrm{~mm}$, cement, and fine aggregate with a fineness modulus less than 2.56, which satisfied the definition of GB175-2007 [45] and GB/T 14685-2011 [46]. Additionally, tap water was adopted in the test. Copperplated steel fibers and polypropylene fibers were utilized in the FRC. The details of the aforementioned materials are summarized in Tables 2 and 3. The amount of superplasticizer in normal concrete was $0.2 \%$ cement by weight. The standard compressive strength of concrete with a $55-70 \mathrm{~mm}$ slump was $50 \mathrm{MPa}$ and was utilized as the test benchmark. This mix proportion was designed according to codes JGJ 55-2011 [47] and CECS38-2004 [48]. Those mix proportions are presented in Table 2. Each test piece was prepared in triple replicates to obtain accurate test data. The compressive and split tensile strength tests were performed on the concrete cubes according to standard for test methods of concrete physical and mechanical properties (GB/T50081-2019) with a loading rate of $7.0 \mathrm{kN} / \mathrm{s}$. A minimum of three specimens $\left(100 \times 100 \times 100 \mathrm{~mm}^{3}\right)$ for each group were tested using the $3000 \mathrm{kN}$ Automatic Concrete Compression Machine. The results of those tests are presented in Table 4.

2.2. Preparation of Specimens. This paper specially designed an I-shaped specimen (Figure 2) to facilitate the fabrication and the monitoring by $3 \mathrm{D}$-DIC instruments. The fabrication process of the specimen was mainly divided into three parts, including old concrete pouring, interface treatment, and new concrete pouring. For easy demolding, it was necessary to coat lubricating oil on the steel mold before the concreting process. The old concrete parts of the specimen were cast with the required compressive strength. Besides, the hand brush and grooving surface and wire bush surface treatment were completed after 5 hours from casting. The mechanical grooving and artificially chiseling method were carried out to process the bond interface after 7 days of curing. The specimen was demolded after 24 hours and maintained at more than $95 \%$ humidity and $20 \pm 2^{\circ} \mathrm{C}$ according to "Method for Testing Mechanical Properties of Common concrete" [49]. After 7 days, the bond interface of old concrete parts was cleaned and carefully moistened for six hours and then put into the steel mold. Before casting the next half parts, the bond agent was immediately applied to the bond interface. Cement paste was adopted as the bond agent with a mix proportion of 1 : 0.5 cement to water. Subsequently, the new concrete of each specimen was cast and then maintained for 24 hours before demolding and then specimens transferred into the standard maintenance environment.

2.3. Surface Treatment. The surface texture of the bond interface was a vital effector to investigate the bond behavior between the new-to-old concrete. To form uneven texture on the bond interface, the hand brush and grooving, wire bush, mechanical grooving, and artificially chiseling method were adopted in this paper. Moreover, those methods were easy to operate and economical and hence widely applied in engineering. The interface treatment tools were commonly utilized in construction sites, including the iron brushes, angle grinder, steel drill, and hammer. The hand brush and grooving method was used the steel drill to create grooves and iron brushes to make the interface rougher, while the wire brush method only adopted the iron brushes. The grooving surface was employed an angle grinder to cut grooves on the interface. Besides, the artificially chiseling method was utilized the steel drill and hammer to chisel the concrete interface.

Surface roughness was a key parameter reflecting the surface texture, which was obtained by the sand cone method (Figure 3). This method was employed in this study owing to the advantages of easy operation, low cost, and high accuracy. The measurement principle of the sand cone 
Table 1: Parameters of direct tension static test specimens.

\begin{tabular}{|c|c|c|c|c|c|}
\hline \multirow{2}{*}{ Series } & \multicolumn{2}{|c|}{ Compressive strength $(\mathrm{MPa})$} & \multirow{2}{*}{ Interfacial angle } & \multirow{2}{*}{ Type of roughness } & \multirow{2}{*}{ Fiber type } \\
\hline & Old concrete & New concrete & & & \\
\hline $\mathrm{C} 50-\mathrm{C} 50-\mathrm{BG}-45^{\circ}$ & 50 & 50 & $45^{\circ}$ & BG & - \\
\hline $\mathrm{C} 50-\mathrm{C} 50-\mathrm{BG}-60^{\circ}$ & 50 & 50 & $60^{\circ}$ & BG & - \\
\hline $\mathrm{C} 50-\mathrm{C} 50-\mathrm{BG}-90^{\circ}$ & 50 & 50 & $90^{\circ}$ & BG & - \\
\hline $\mathrm{C} 50-\mathrm{C} 40-\mathrm{BG}-45^{\circ}$ & 50 & 40 & $45^{\circ}$ & BG & - \\
\hline C50-C60-BG- $45^{\circ}$ & 50 & 60 & $45^{\circ}$ & BG & - \\
\hline $\mathrm{C} 50-\mathrm{C} 50-\mathrm{MG}-45^{\circ}$ & 50 & 50 & $45^{\circ}$ & MG & - \\
\hline $\mathrm{C} 50-\mathrm{C} 50-\mathrm{AC}-45^{\circ}$ & 50 & 50 & $45^{\circ}$ & $\mathrm{AC}$ & - \\
\hline $\mathrm{C} 50-\mathrm{C} 50-\mathrm{WB}-45^{\circ}$ & 50 & 50 & $45^{\circ}$ & WB & - \\
\hline SC50-C50-BG- $45^{\circ}$ & 50 & 50 & $45^{\circ}$ & BG & Steel fiber \\
\hline PPC50-C50-BG- $45^{\circ}$ & 50 & 50 & $45^{\circ}$ & BG & Polypropylene fiber \\
\hline SPC50-C50-BG- $45^{\circ}$ & 50 & 50 & $45^{\circ}$ & BG & Steel and polypropylene fiber \\
\hline SPC50-C50-BG-45 & & & $\begin{array}{r}\text { Note: (1) refers to } \\
\text { compressive st } \\
\text { corresponding } \\
\text { treatment. BG, } \\
\text { surface, wire bus } \\
\text { treatme }\end{array}$ & $\begin{array}{l}\text { ne type of the old and } \\
\text { ngth. (3) refers to the } \\
\text { ompressive strength. } \\
\text { 3, MG, and AC refer } \\
\text { mechanical grooving } \\
\text { method, respectivel }\end{array}$ & $\begin{array}{l}v \text { concrete. (2) is corresponding } \\
\text { pe of the new concrete. (4)is } \\
\text { denotes the type of surface } \\
\text { the hand brush and grooving } \\
\text { nd artificially chiseling surface } \\
\text { is interfacial angle. }\end{array}$ \\
\hline
\end{tabular}

Table 2: Concrete mix proportion.

\begin{tabular}{|c|c|c|c|c|c|c|c|}
\hline Series & $\begin{array}{c}\text { Cement content } \\
\left(\mathrm{kg} \cdot \mathrm{m}^{3}\right)\end{array}$ & $\begin{array}{l}\text { Water content } \\
\quad\left(\mathrm{kg} \cdot \mathrm{m}^{3}\right)\end{array}$ & Sand content $\left(\mathrm{kg} \cdot \mathrm{m}^{3}\right)$ & Gravel content $\left(\mathrm{kg} \cdot \mathrm{m}^{3}\right)$ & Plasticizer (kg.m $\left.{ }^{3}\right)$ & Steel fiber (\%) & PPF (\%) \\
\hline $\mathrm{C} 40$ & 400 & 180 & 778 & 1042 & 0.5 & - & - \\
\hline C50 & 500 & 180 & 559 & 1136 & 0.5 & - & - \\
\hline SC & 500 & 180 & 559 & 1136 & 0.5 & 0.250 & - \\
\hline PC & 500 & 180 & 559 & 1136 & 0.5 & - & 0.250 \\
\hline SPC & 500 & 180 & 559 & 1136 & 0.5 & 0.125 & 0.125 \\
\hline C60 & 600 & 190 & 570 & 1122 & 0.6 & - & - \\
\hline
\end{tabular}

Note. C40, C50, and C60 refer to the normal concrete with compressive concrete strength of 40, 50, and $60 \mathrm{MPa}$, respectively. SC is the steel fiber-reinforced concrete. PC is the polypropylene fiber-reinforced concrete with compressive concrete strength of $50 \mathrm{MPa}$. SPC refers to the hybrid fiber-reinforced concrete.

TABle 3: Performance index of steel and polypropylene fiber.

\begin{tabular}{lccccccc}
\hline Fiber type & $\begin{array}{c}\text { Density } \\
\left(\mathrm{g} / \mathrm{cm}^{3}\right)\end{array}$ & $\begin{array}{c}\text { Diameter } \\
(\mu \mathrm{m})\end{array}$ & $\begin{array}{c}\text { Length } \\
(\mathrm{mm})\end{array}$ & $\begin{array}{c}\text { Tensile strength } \\
(\mathrm{MPa})\end{array}$ & $\begin{array}{c}\text { Bending strength } \\
(\mathrm{MPa})\end{array}$ & $\begin{array}{c}\text { Modulus of elasticity } \\
(\mathrm{GPa})\end{array}$ & $\begin{array}{c}\text { Elongation at break } \\
(\%)\end{array}$ \\
\hline Polypropylene fiber & 0.91 & 30 & 12 & $550-700$ & - & $3.5-6.8$ & 21 \\
Steel fiber & 7.80 & 100 & 13 & $>3000$ & 686 & 200 & 3.2 \\
\hline
\end{tabular}

TABLE 4: The compressive and split tensile strength of specimens.

\begin{tabular}{|c|c|c|c|c|c|c|}
\hline \multirow[t]{2}{*}{ Series } & \multicolumn{2}{|c|}{$\begin{array}{c}\text { Compressive } \\
\text { strength (MPa) }\end{array}$} & \multicolumn{2}{|c|}{$\begin{array}{c}\text { Average } \\
\text { compressive } \\
\text { strength }(\mathrm{MPa})\end{array}$} & \multirow{2}{*}{$\begin{array}{l}\text { Split tensile strength }(\mathrm{MPa}) \\
28 \text { days }\end{array}$} & \multirow{2}{*}{$\begin{array}{l}\text { Average split tensile strength }(\mathrm{MPa}) \\
\qquad 28 \text { days }\end{array}$} \\
\hline & 7 days & 28 days & 7 days & 28 days & & \\
\hline \multirow{3}{*}{$\mathrm{C} 40$} & 36.34 & 44.50 & \multirow{3}{*}{36.84} & \multirow{3}{*}{46.7} & 2.86 & \multirow{4}{*}{2.98} \\
\hline & 35.95 & 47.24 & & & 3.13 & \\
\hline & 38.25 & 45.9 & & & 2.95 & \\
\hline \multirow{3}{*}{ C50 } & 42.49 & 52.51 & \multirow{3}{*}{41.44} & \multirow{3}{*}{55.69} & 3.28 & \\
\hline & 41.36 & 56.8 & & & 3.34 & \multirow[t]{2}{*}{3.35} \\
\hline & 40.47 & 57.74 & & & 3.39 & \\
\hline \multirow{3}{*}{ C60 } & 43.19 & 52.51 & \multirow{3}{*}{43.09} & \multirow{3}{*}{60.2} & 3.55 & \multirow{3}{*}{3.53} \\
\hline & 43.09 & 56.80 & & & 3.47 & \\
\hline & 42.98 & 57.74 & & & 3.57 & \\
\hline
\end{tabular}



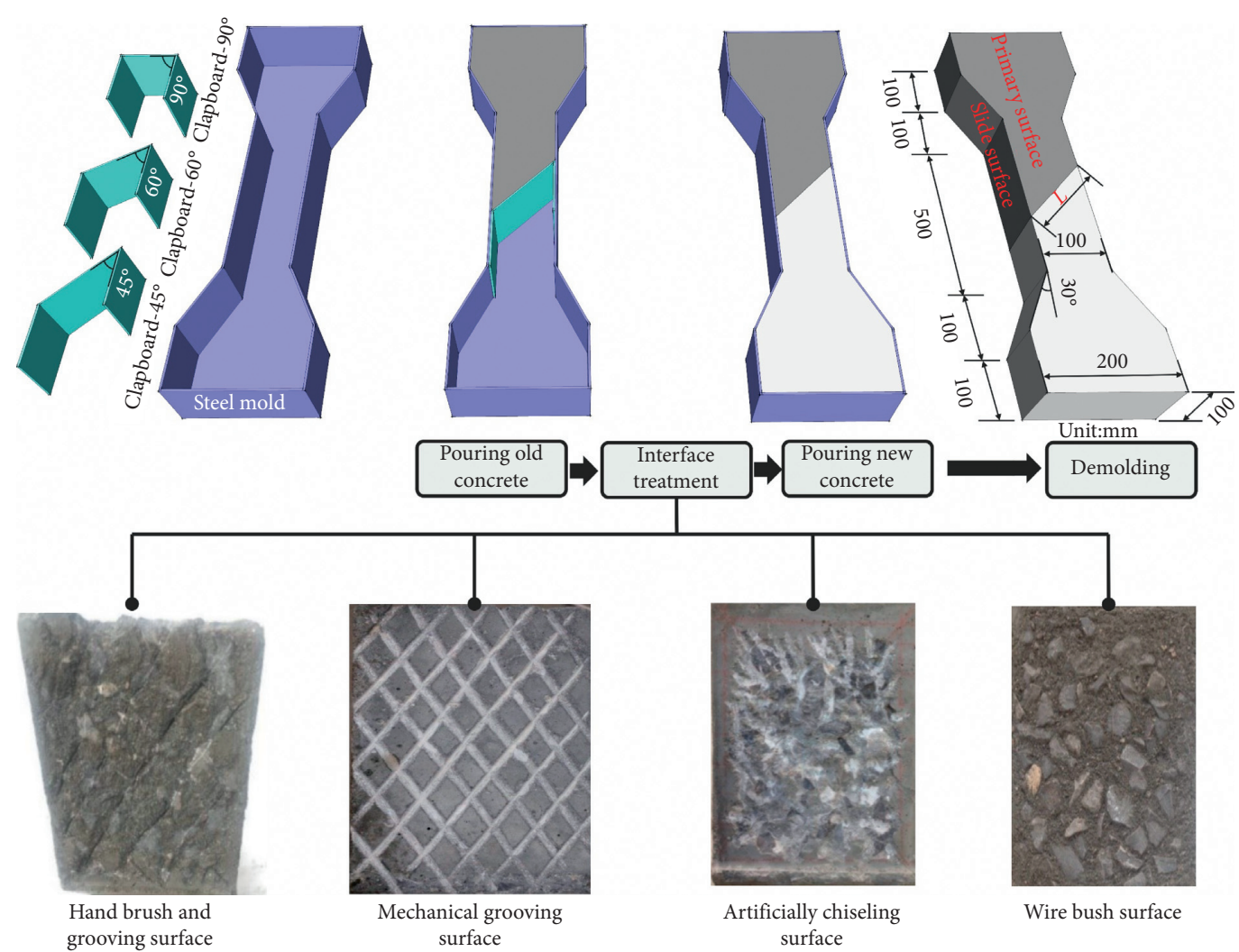

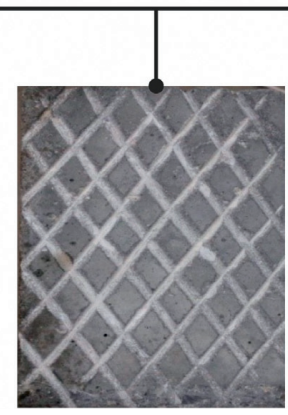

Mechanical grooving surface

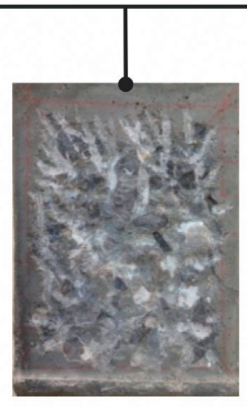

Artificially chiseling surface

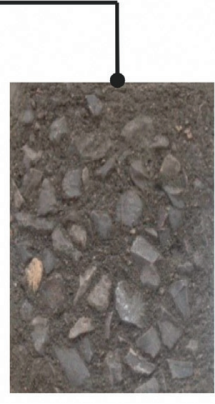

Wire bush surface

Figure 2: Specimen preparation.

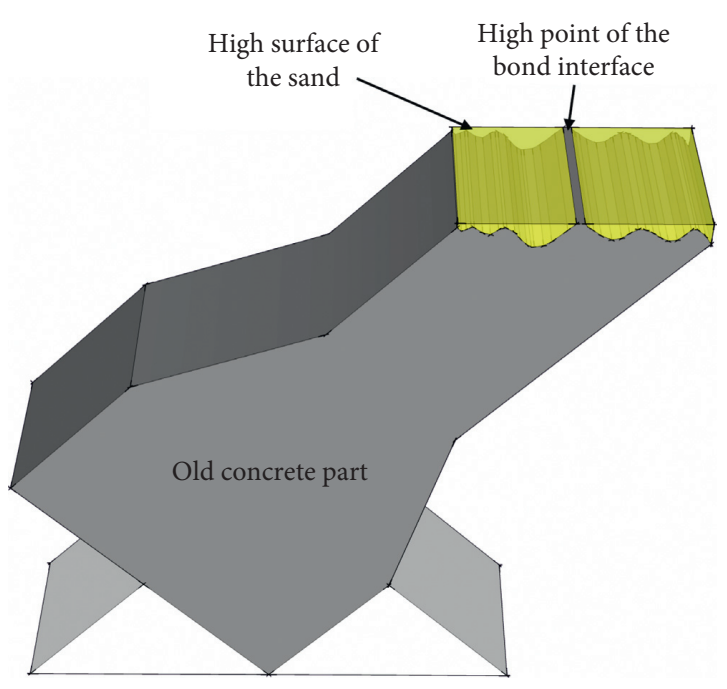

Figure 3: Sand cone method.

method was as follows: the measuring surface was placed horizontally and surrounded by four flat plates. Then, the highest plane of the flat plate was levelled with the highest point of the measuring surface as shown in Figure 3. After that, the fine sand was poured onto the measuring surface and levelled with a flat plate. The sand volume $(V)$ was measured by a graduated cylinder, and the surface roughness $(D)$ of the measuring surface area $(S)$ was exemplified by the average fill depth. The calculation method was used to determine the average sand fill depth as follows:

$$
D=\frac{V}{S}
$$

$D$ is the average sand fill depth, $V$ is the sand volume, and $S$ is the area of the substrate surface.

2.4. Methods of Testing. The axial tensile experiment (Figure 4(a)) was performed in the Structure and Seismic Laboratory of Chang'an University in China, employing an electrohydraulic servo static testing instrument. The spherical hinge can automatically adjust the loading direction of the specimen during the experiment and reduce the eccentricity. Therefore, the testing instrument can offer force perpendicular to the top of the specimen owning to two spherical hinges in the bottom of this apparatus. Besides, in order to prevent the specimen from sliding with the jig during the experiment, two adjusting bolts were installed on the upper and lower ends of the jig, respectively. It was extremely convenient to tightly fasten the specimen in the jig by adjusting the length of the upper and lower adjusting bolts (Figure 4(a)). The specimens were loaded by load control method with $2 \mathrm{kN} / \mathrm{min}$. The bond stress $(\sigma)$ can be calculated as follows:

$$
\sigma=\frac{F \sin \theta}{A},
$$

where the $F$ refers to the maximum load subjected to the specimen. $A$ is the interface surface $(A=H L) . H$ is the specimen height. $L$ is the effective bond length along the interface angle, as shown in Figure 2. $\theta$ denotes the angle 


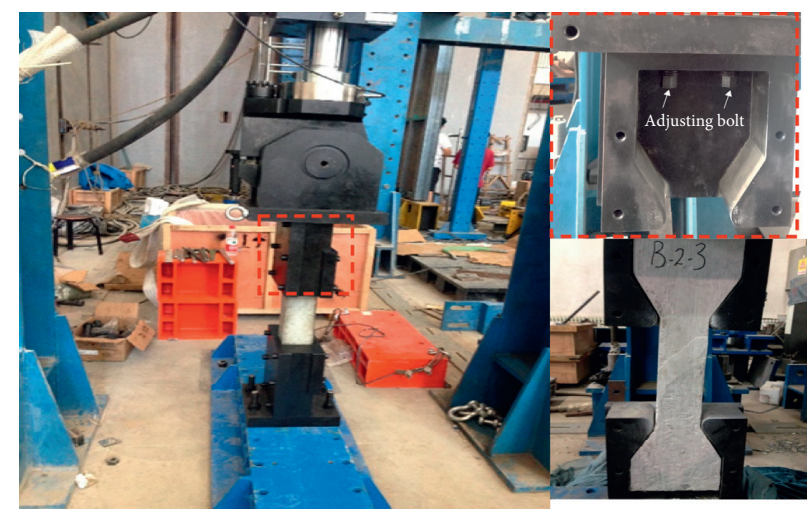

(a)

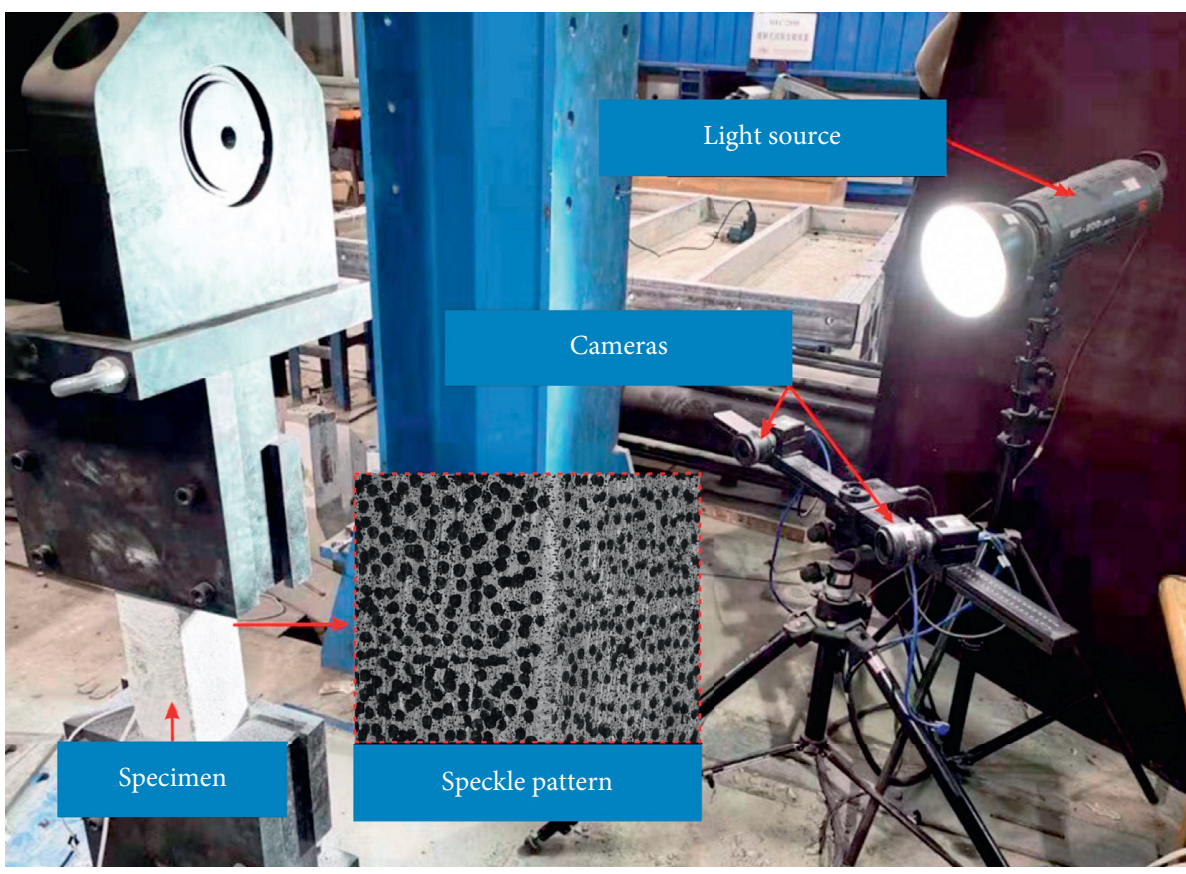

(b)

Figure 4: Schematic diagram of test setup. (a) Schematics of the loading instrument. (b) Schematics of the 3D-DIC instrument.

between the interface and the longitudinal direction of the specimen.

The 3D-DIC method is a visual, noncontact, and threedimensional deformation measurement technique, which is widely used to study a wide variety of material performances. It is adapted to measure and analyze surface texture, displacement, and strain on the surface of the monitoring object, as well as obtain three-dimensional strain field data with a visual display. The 3D-DIC apparatus consist of an adjustable measuring head, two cameras, a control box, and a computer. The signal link between hardware and software is realized through the control box. Two cameras collect scattered images of objects at each deformation stage, and this system utilizes the digital image correlation algorithm to match the deformation points on the surface of objects. The $3 \mathrm{D}$ coordinates of the points are calculated by reconstructing the object surface based on the parallax data of each point and the precalibrated camera parameters. Subsequently, the displacement field of the object surface is obtained by comparing the changes of the $3 \mathrm{D}$ coordinates for each point and deformation state in the measurement area, and the object surface strain field is further calculated. The 3D-DIC device was set in front of the specimen (Figure 4(b)) and acquired data at $1 \mathrm{~Hz}$ throughout the experiment. Besides, the specimen of the scanning electron microscope observation was taken from fracture interfaces of the new-to-old concrete specimen.

\section{Experimental Results}

The results obtained from the axial tensile experiment are summarized in Table 5. The failure modes, bond strengths between the new-to-old concrete interface, and variation of strain distributions of specimens were systematically analyzed. Because the elastic modulus of concrete is relatively large, the variation of principal strain on the specimen surface monitored by 3D-DIC is relatively flat, while that of vertical strain is on the contrary. Therefore, this paper 
Table 5: Axial tensile testing results.

\begin{tabular}{|c|c|c|c|c|c|c|}
\hline Series & $\begin{array}{c}\text { Interfacial } \\
\text { roughness } \\
(\mathrm{mm})\end{array}$ & Bond strength $(\mathrm{MPa})$ & $\sigma(\mathrm{MPa})$ & $\tau(\mathrm{MPa})$ & $\sigma$-Deviation (\%) & Failure mode \\
\hline $\mathrm{C} 50-\mathrm{C} 50-\mathrm{BG}-45^{\circ}$ & 2.5 & 1.615 & 1.142 & 1.142 & 0.00 & $A$ \\
\hline C50-C50-BG-60 & 2.5 & 1.179 & 1.021 & 0.590 & -10.60 & $A$ \\
\hline C50-C50-BG-90 & 2.5 & 1.205 & 1.205 & 0 & -25.39 & $A$ \\
\hline $\mathrm{C} 50-\mathrm{C} 40-\mathrm{BG}-45^{\circ}$ & 2.5 & 1.547 & 1.094 & 1.094 & -4.20 & $A$ \\
\hline C50-C60-BG- $45^{\circ}$ & 2.5 & 1.899 & 1.343 & 1.343 & 17.60 & $A$ \\
\hline C50-C50-MG- $45^{\circ}$ & 3.0 & 1.534 & 1.085 & 1.085 & -4.99 & $A$ \\
\hline $\mathrm{C} 50-\mathrm{C} 50-\mathrm{AC}-45^{\circ}$ & 3.0 & 2.084 & 1.474 & 1.474 & 29.07 & $B$ \\
\hline $\mathrm{C} 50-\mathrm{C} 50-\mathrm{WB}-45^{\circ}$ & 2.5 & 1.941 & 1.373 & 1.373 & 20.23 & $A$ \\
\hline SC50-C50-BG- $45^{\circ}$ & 2.5 & 3.655 & 2.585 & 2.585 & 126.36 & $B$ \\
\hline PPC50-C50-BG- $45^{\circ}$ & 2.5 & 2.155 & 1.524 & 1.524 & 33.45 & $C$ \\
\hline SPC50-C50-BG- $45^{\circ}$ & 2.5 & 2.511 & 1.776 & 1.776 & 55.52 & $B$ \\
\hline
\end{tabular}

Note. $\sigma$ and $\tau$ refer to bond stress perpendicular and along the new-to-old concrete interface, respectively. $\sigma$-Deviation refers to the increase or decrease ratio of the tensile stress for specimens to that of specimen C50-C50-BG-45. A, B, and C denote the adhesive failure, partial adhesive failure, and cohesive failure modes, respectively.

employed the vertical strain to describe the variation of strain distribution.

3.1. Failure Modes. The typical bond failure modes observed in axial tensile experiments are shown in Figure 5. The bond failure mode was subdivided into 3 categories: adhesive failure, partial adhesive failure, and cohesive failure. The details of specimen failure modes are listed in Table 5. The adhesive failure mainly occurred at the interface (Figure 5(a)) and could be described as pure interface failure. There were no flaky and elongated particle aggregates that could be seen on both sides, while only the cement matrix was on the interface. The failure modes of specimens were mainly the adhesive failure, except for specimens with the addition of fibers and the interface adopted the artificially chiseling treatment method. Nevertheless, the partial adhesive failure mode was interface failure with partially substrate failure in which monolithic failure occurred in the weakest concrete matrix, as shown in Figure 5(b). Both sides of the interface were uneven in which the aggregates either broken or pulled out. It can be seen that the failure followed the bond angle up to a specific point; then the failure crack path was changed to cross the weakest concrete. The specimens with fibers were prone to emerge the partial adhesive failure subjected to axial tensile loading. This phenomenon was attributed to the fiber contribution on the bond strength at the new-to-old concrete interface, thus increasing the strength of the interface zone concrete matrix higher than the weak concrete parts. The third failure mode is the cohesive failure, namely overlaid failure, as shown in Figure 5(c). The specimen fractured at the new concrete part indicating a superior bond behavior, which reflected the remarkable effect of fiber incorporation for enhancing the bond strength. Moreover, there were no cracks observed at the new-to-old concrete interface, and the whole crack causing the failure was entirely located at the neck of the overly concrete (new concrete). The SPC50-C50-BG- $45^{\circ}$ specimen generated this type of failure mainly attributed to the positive hybrid effect of steel and polypropylene fiber. It will expose part of the fibers during the interface treatment, and this part of the fibers form a FRC interface transition zone with the new concrete. Hence, this transition zone made the strength variation from the FRC to common concrete relatively gentle, thus avoiding the stress concentration in the interface area.

3.2. Bond Strength. The axial bond strength between the new-to-old concrete interface is illustrated in Figure 6. In the case of the fiber addition, the axial tensile strength of specimens SC50-PC50-BG-45 ${ }^{\circ}$, PPC50-PC50-BG- $45^{\circ}$, and SPFC50-PC50-BG- $45^{\circ}$ was boosted by $126.36 \%, 33.45 \%$, and $55.52 \%$ compared with the specimen C50-C50-BG- $45^{\circ}$. It indicated that the fiber addition to old concrete can significantly improve the bond strength of new-to-old concrete interface. During the treatment of FRC interface, a part of fibers was exposed after the concrete matrix was broken, while a portion of that fiber remained in the old concrete matrix. Subsequently, the exposed fibers were rewrapped by the concrete matrix as the applicating of new concrete. It was the same as adding fibers to the new concrete in the interface area, thereby enhancing the bond strength. Therefore, when concrete is applicated in multiple layers, fibers can be incorporated into the concrete only at the interface area. This avoids the difficulty of producing a large amount of FRC, and the utilization of a small amount of FRC can also effectively enhance the bond strength of the new-to-old concrete interface.

In the case of surface treatment type, the roughness of the artificially chiseling interface was the largest among all the specimens, yet the bond strength of the artificially chiseling interface was $35.85 \%$ higher than that of the mechanical grooving interface. It indicated that the more uneven the interface texture (Figure 2), the stronger the bond strength of the interface. Besides, the bond behavior in terms of artificially chiseling and wire bush interface showed the excellent performance, wherein the bond strength has increased by $29.07 \%$ and $20.23 \%$ over that of hand brush and grooving interface. Moreover, from Figure 2, a large amount 


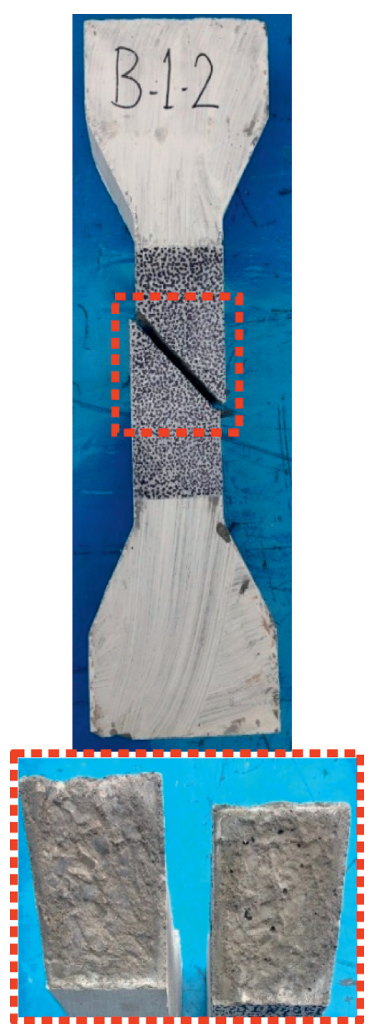

(a)

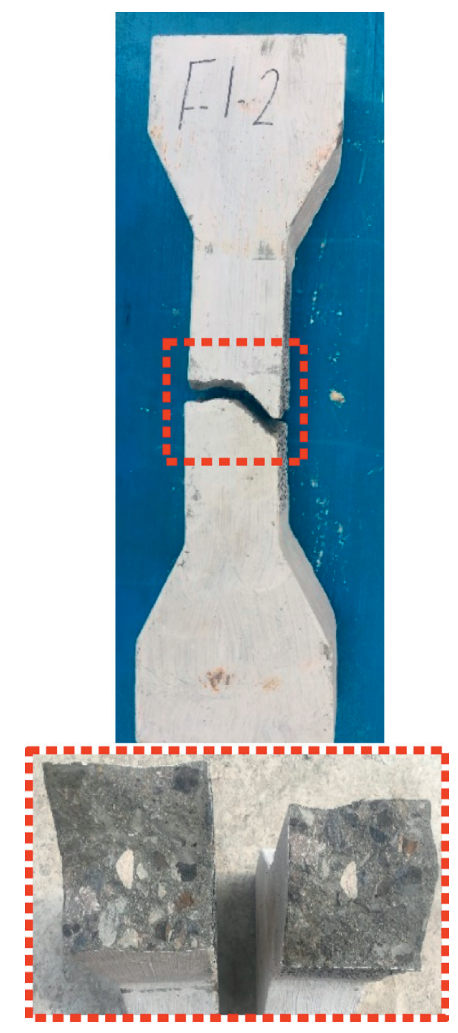

(b)

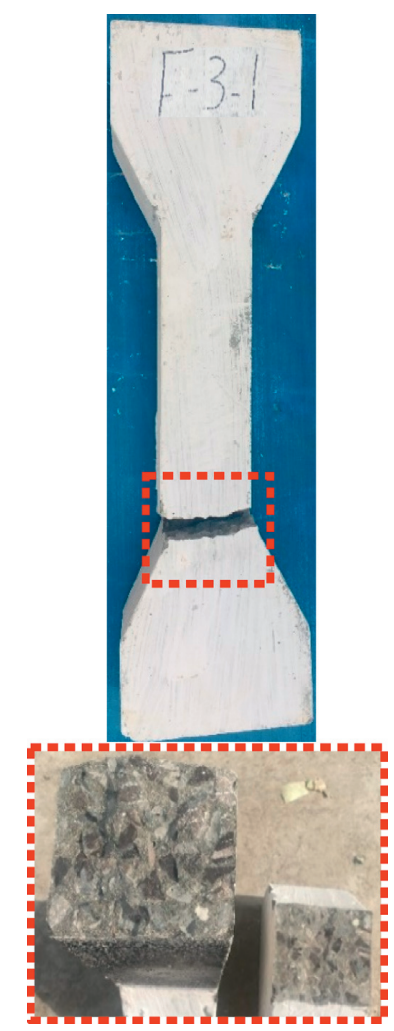

(c)

Figure 5: Failure modes. (a) Adhesive failure. (b) Partial adhesive failure. (c) Cohesive failure.

of coarse aggregate was exposed at the artificially chiseling and wire bush treated interface, while there was a large amount of concrete matrix at the hand brush and grooving, and mechanical grooving treated interface. The density and strength of aggregates are higher than the concrete matrix formed by cement and sand. Besides, the surface texture of aggregate is rougher than that of concrete matrix; hence, the bond strength between the concrete matrix and aggregate is larger than the bond strength among concrete matrixes.

As for the concrete strength grade of new concrete, the bond strength of specimens C50-C50-BG-45 and C50-C60BG- $45^{\circ}$ was increased by $4.39 \%$ and $22.76 \%$ compared with that of specimen C50-C40-BG- $45^{\circ}$, respectively. This phenomenon was consistent with the effect of fresh concrete strength. When new concrete is in contact with an old concrete interface, it will absorb some water from the fresh concrete, resulting in high water-cement ratio hydration at the interface and enhancing its strength.

As for interface angle, the bond strength of specimens C50-C50-BG- $60^{\circ}$ and C50-C50-BG- $90^{\circ}$ was decreased by $10.60 \%$ and $55.52 \%$ compared with the specimen C50-C50BG $-45^{\circ}$, respectively. It reflected that increasing the interface bonding area can significantly enhance the bond strength.

3.3. Variation in Strain Distribution. The specimen surface images were taken during axial tensile loading using two cameras, whereafter the images were analyzed and calculated utilizing correlation methods to obtain the surface strains.
Besides, the DIC data of specimens C50-C50-BG-60 and C50-C50-BG- $90^{\circ}$ will not be presented in this section due to insufficient calculation accuracy. The strain distribution of specimens tested in the experimental program was described as follows. As shown in Figure 4(b), the specimen monitored two adjacent surfaces (primary and side surface, as shown in Figure 2), and one of the phenomenally obvious surfaces was selected for presentation in this paper.

\subsubsection{Effect of Adding Fibers to the Old Concrete.} Figure 7 presents the vertical surface strain variation of the specimens with fibers. As shown in Figure 7(a1), most of the strain nephogram had the same color. At this stage of loading, the specimen's strain was relatively regular, and most of the region was in a steady tension state. As the strain increased (Figure 7(a2)), the location of the first crack was observed at the interface. With further increase of the loading, the maximum strain value has been registered and only expanded in length indicated by arrows in Figure 7(a3). At the ultimate loading stage, the crack end fully expanded at the interface as indicated by the maximum value of the strain, which followed the specimen interface.

As for specimen SC50-C50-BG-45, the strain nephogram showed that the tensile strain of the FRC specimen was complex, and the maximum strain appeared in different locations. With the increasing of the load, the maximum strain was concentrated on the right side of the interface area, as shown in Figure 7(b2). Meanwhile, many horizontal 


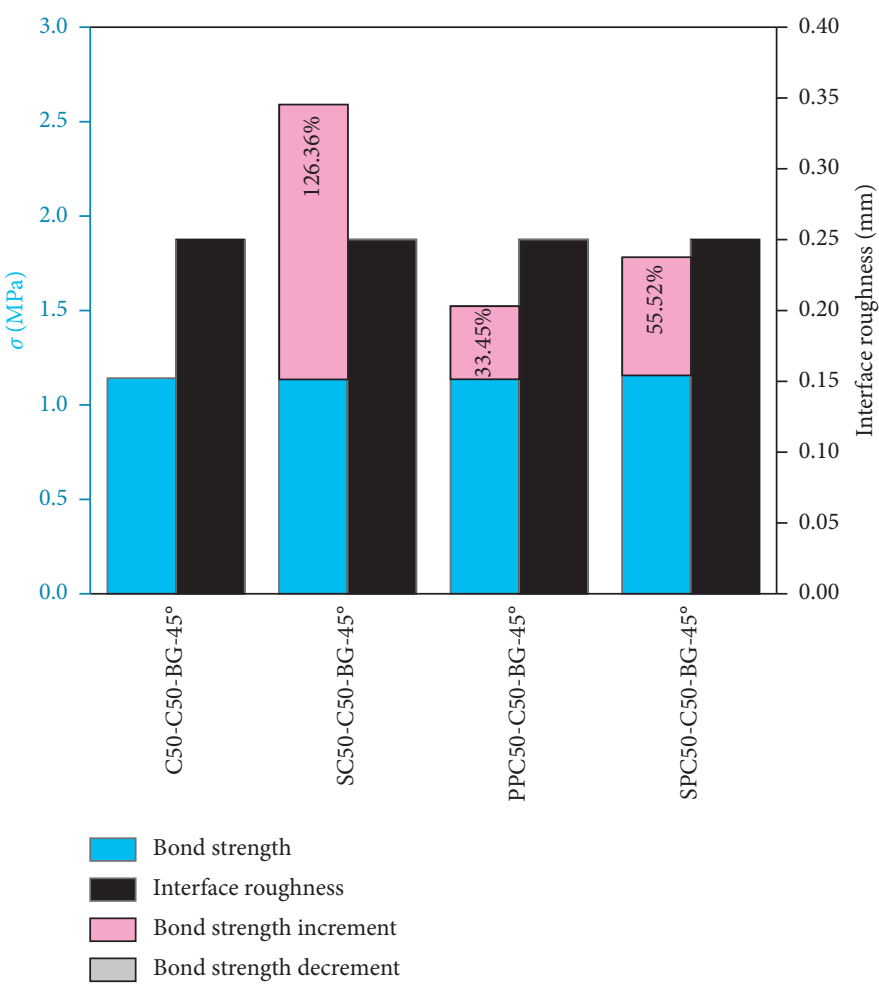

(a)

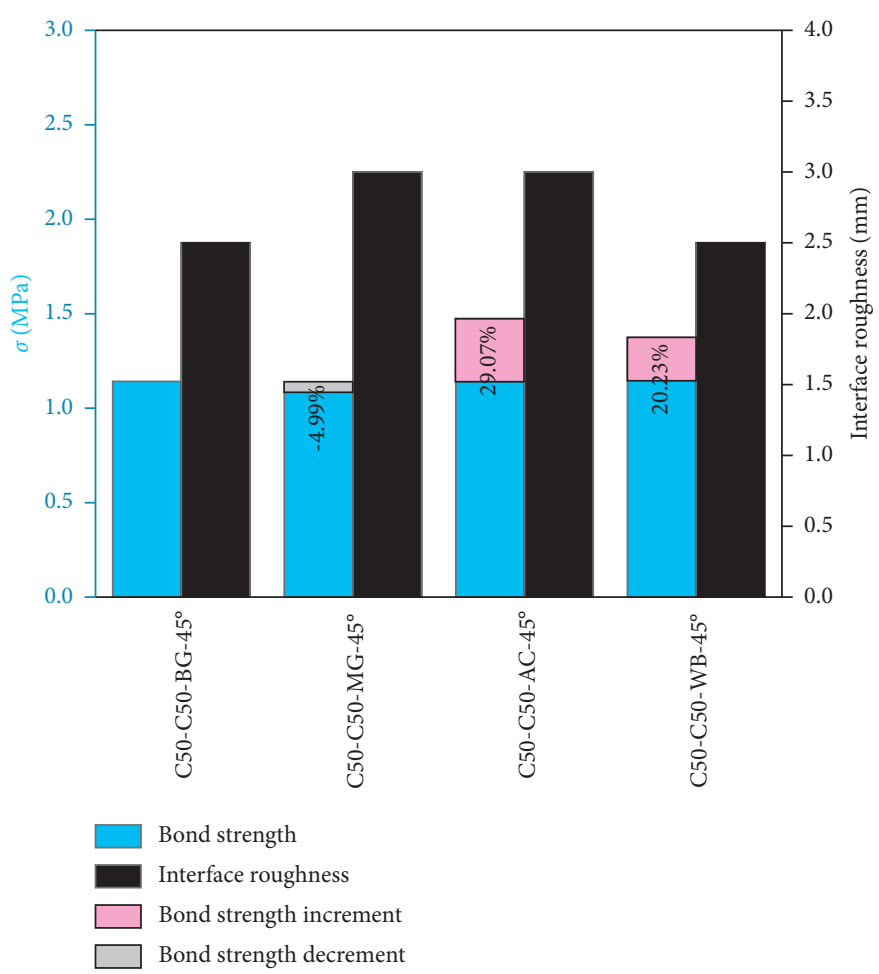

(c)

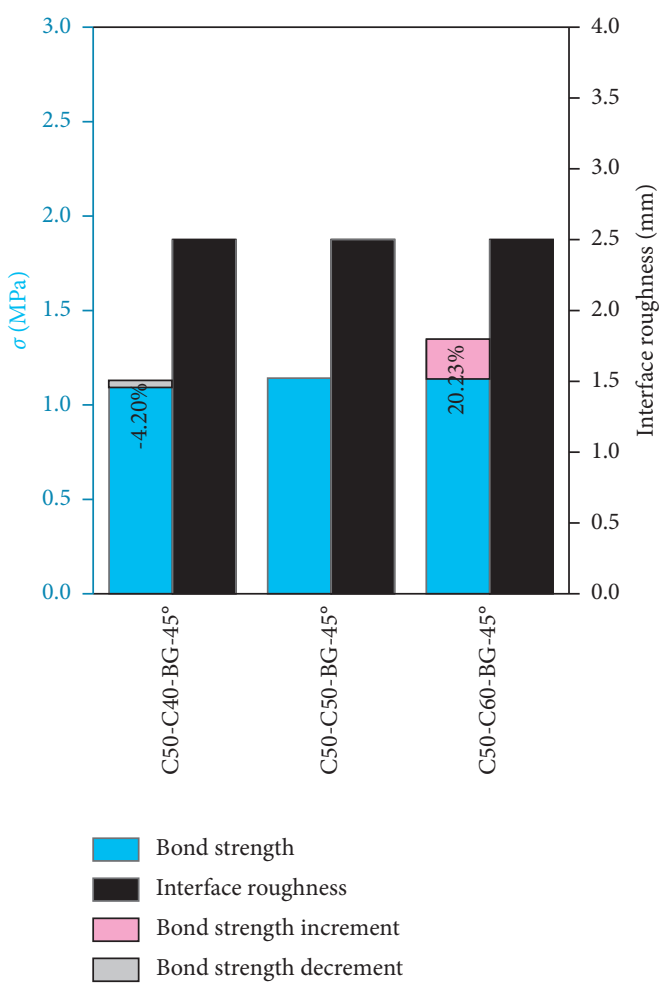

(b)

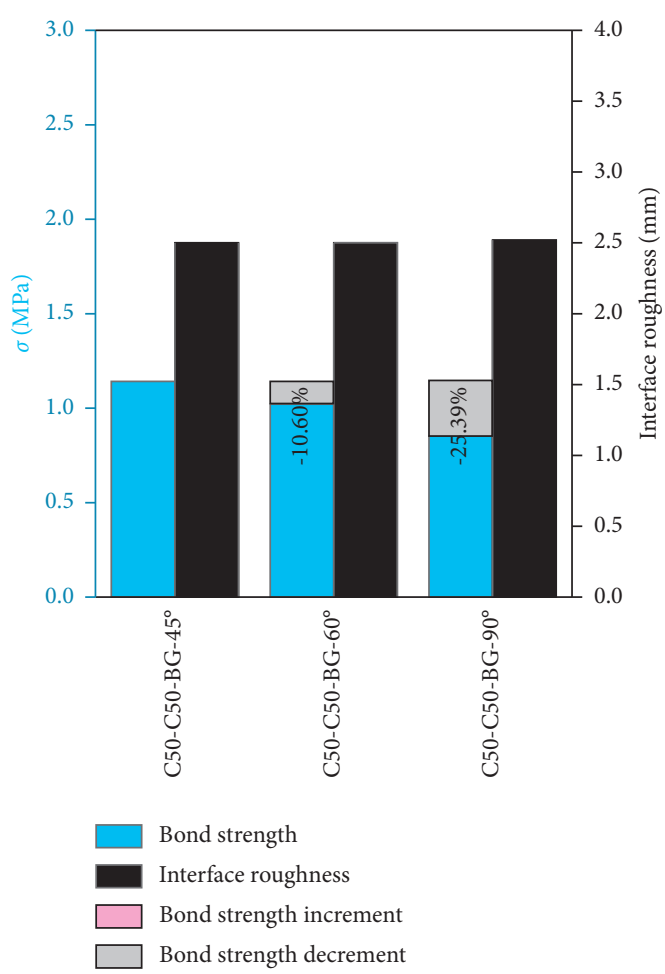

(d)

Figure 6: Axial tensile bond strength between the new and old concrete. (a) Fiber type. (b) Concrete strength grade. (c) Surface treatment type. (d) Interfacial angle. 

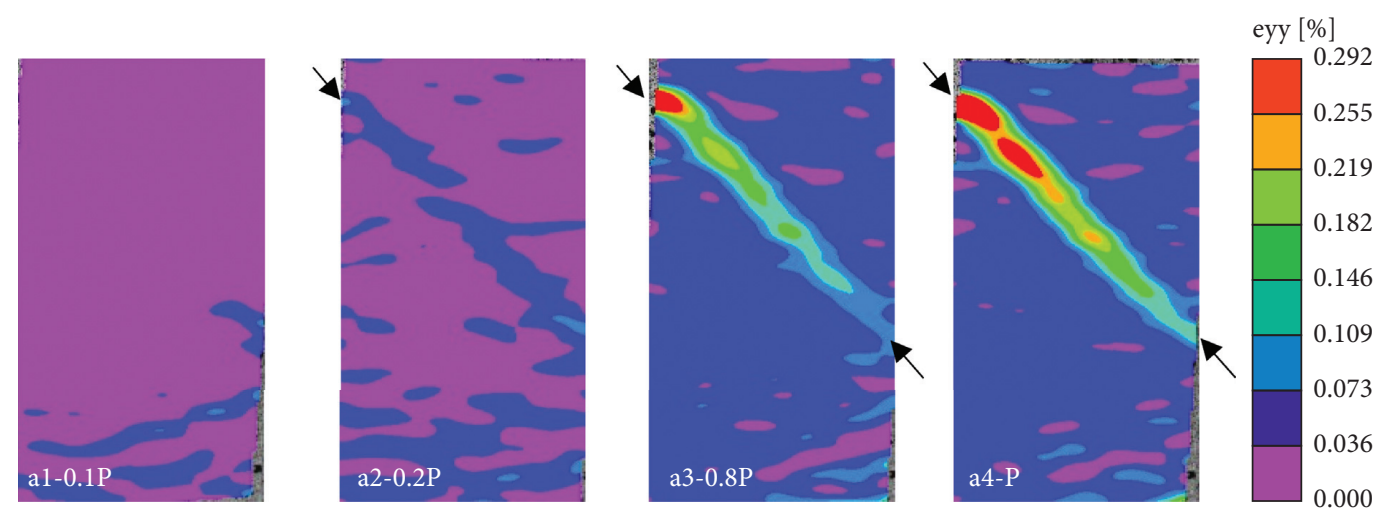

(a)
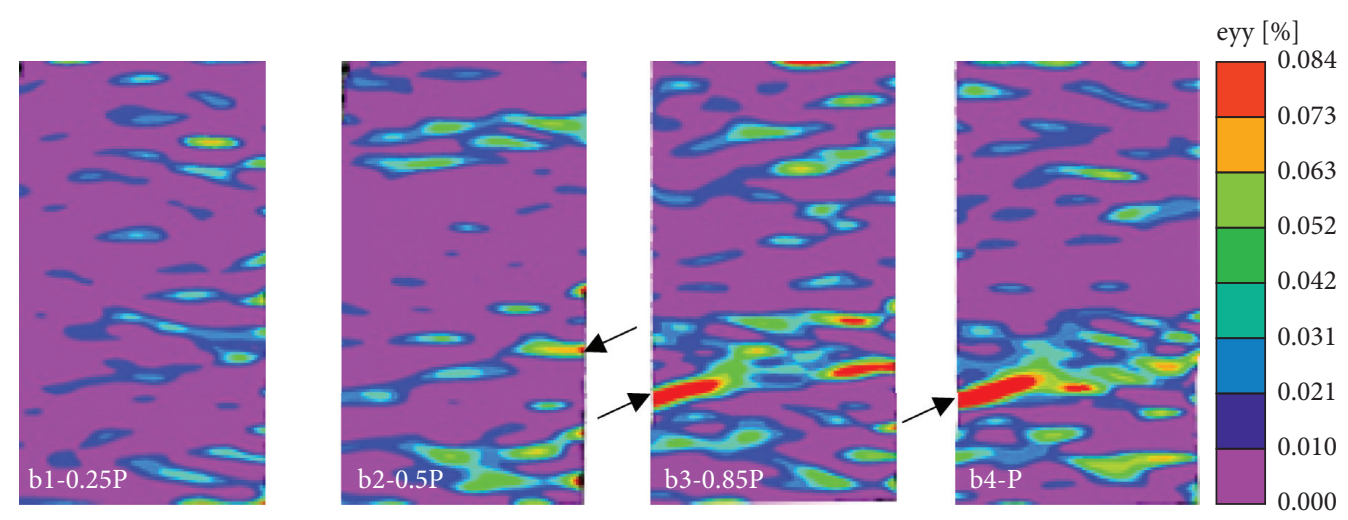

(b)
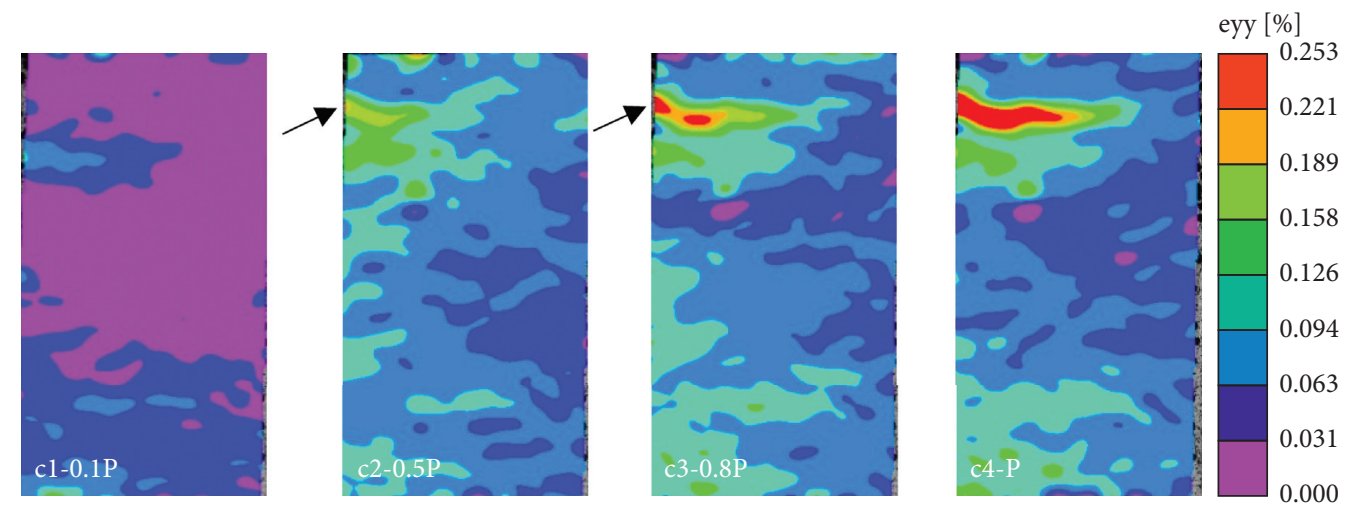

(c)
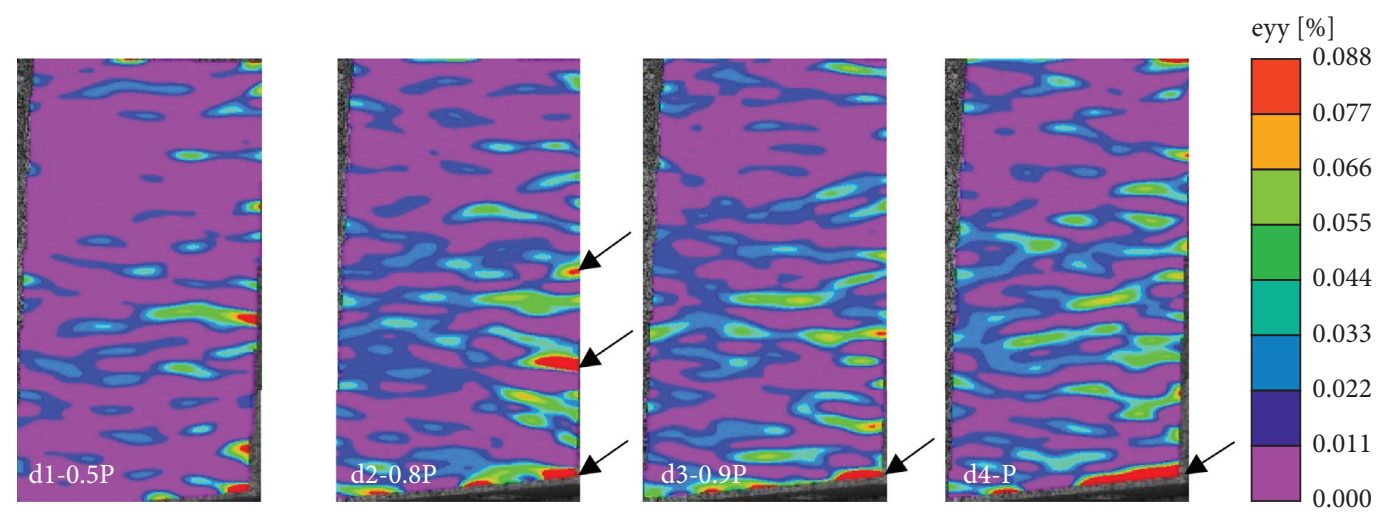

(d)

FIGURE 7: Vertical strain field for specimen with various fibers at different loading stages: (a) C50-C50-BG-45 (primary surface), (b) SC50C50-BG- $45^{\circ}$ (primary surface), (c) PC50-C50-BG- $45^{\circ}$ (primary surface), and (d) SPC50-C50-BG- $45^{\circ}$ (primary surface). 
microcracks were randomly distributed on the surface. It was mainly due to the fact that the cement hydration reaction was exothermic, and the temperature reduction of concrete matrix leaded to generate shrinkage microcracks, which were easy to widen under the axial tensile loading. As further increasing of the load, the direction of crack development has changed and then crossed the region below the interface (Figure 7(b3)). Besides, the crack located in the specimen lower only expanded in the length without the width, yet the other microcrack stress areas were reduced a little in the meantime. At the ultimate load, the crack propagated to the entire width of the specimen (Figure 7(b4)) and registered the highest bond strength compared with other specimens. This phenomenon was due to the absence of steel fiber on the old concrete, which could not inhibit the crack propagation.

For specimen PC50-C50-BG- $45^{\circ}$, the load increasing leaded to the maximum strain appearing at the left side of the interface area as shown in Figure 7(c2). With further increasing of the applied load, the crack propagation has changed the direction and cross the area upper the interface, which was located on the left side of the common concrete. At the ultimate load (Figure 7(c4)), the crack propagated in length at the same location until the specimen was damaged. The phenomenon was the same as that of specimen SC50-C50-BG- $45^{\circ}$.

Figure $7(\mathrm{~d})$ shows the strain nephogram of specimen SPC50-C50-BG- $45^{\circ}$ under axial tension load. With the increase of the applied load, the strain distribution showed that numerous cracks were generated at different locations in the specimen, as indicated by arrows in Figure 7(d2). Besides, there were few cracks in the upper surface of the FRC, while more cracks appeared on the lower common concrete surface. With further increase of the applied load, it was obvious that the cracks located in the common concrete surfaces developed more rapidly in terms of the width, length, and quantity, as shown in Figure $7(\mathrm{~d} 3)$. The phenomenon revealed that the fiber addition could effectively inhibit the microcracks development. Nevertheless, cracks on the common concrete surface continued to extend outward until the specimen was damaged, as shown in Figure 7(d4).

In summary, the strain nephogram of specimens cooperating with fibers under axial tensile loading was well agreed with the experimental observation. Moreover, at the failure stage of loading, the maximum strain location obtained from DIC was the same as the location of specimen failure. This verified the effectiveness of adopting the DIC technique to monitor and forecast the concrete structure behavior. Besides, the number of microcracks on the FRC surfaces was less than that in common concrete, and most microcracks were horizontal cracks perpendicular to the force direction except for the cracks along the interface area. Moreover, after the development of the major crack, the strain of the microcracks located in the major crack can be reduced, and the further away from the major crack, the more obvious the strain reduction.

3.3.2. Effect of Interface Treatment Method. In this section, the specimen strain nephogram in terms of various interface treatment methods, including the hand brush and grooving surface, wire brush, mechanical grooving, and artificially chiseling interface treatment method, was presented.

Figures 7 (a) and 8 exhibit the strain nephograms of specimens $\mathrm{C} 50-\mathrm{C} 50-\mathrm{BG}-45^{\circ}$, C50-C50-WB- $45^{\circ}$, and C50C50-MG- $45^{\circ}$, respectively. It can be seen from Figures $7(\mathrm{a} 1), 8(\mathrm{a} 1)$, and $8(\mathrm{~b} 1)$ that most of the strain nephogram area has the same color. At this stage of loading, the specimen strain was relatively regular, and most of the regions were in a steady tension state. With the increase of the applied load, the strain values were increased accordingly, and the new-to-old concrete interface became the first crack position. Besides, it was interesting to find that the cracks on the specimen surfaces were almost always horizontal, except for the crack at the interface, which was inclined along with the interface. That was attributed to that the interface was the weakest area as indicated by the arrow in Figures 7(a2), 8(a2), and 8(b2). With further increase of the loading, the maximum strain value has been registered and expanded in length at the position indicating by arrows in Figures $7(\mathrm{a} 3), 8(\mathrm{a} 3)$, and 8(b3). At the ultimate loading stage, all specimens exhibited the same behavior in which the full expansion of the crack at the interface followed the specimen bond angle. This indicated that those types of roughness have almost no effect on inhibiting the crack propagation from passing through the new-to-old concrete interface.

Figure $8(\mathrm{c})$ presents the strain nephogram of specimen C50-C50-AC- $45^{\circ}$ corresponding to different levels of loading. At the initial stage of loading, the specimen C50$\mathrm{C} 50-\mathrm{AC}-45^{\circ}$ showed the same behavior as others under steady tension state (Figure $8(\mathrm{c} 1)$ ), wherein the strain distribution was relatively regular. With increasing of the applied load, the crack initiated at the interface, and this can be clearly seen from the maximum strain value in Figure $8(\mathrm{c} 2)$. With the continued increase of the applied load, the effect of partially chipped surface treatment appeared, which changed the crack development path, and the major crack crossed the new concrete part of the specimen outside the interface region (Figure 8(c4)).

In general, the majority of the specimen damage developed from microcracks at the edge of the interface and there was a clear region of strain concentration during the initial loading. It revealed that the new-to-old concrete interface is more likely to become the damage location, once the ultimate strain registers on the specimen surface. Therefore, the DIC technique can be adapted to predict the crack development and damage location of the structure.

\subsubsection{Effect of Concrete Compressive Strength of New} Concrete. Figures 7 (a) and 9 present the strain nephogram of specimens C50-C50-BG- $45^{\circ}$, C50-C40-BG- $45^{\circ}$, and C50C60-BG- $45^{\circ}$, respectively. It can be seen from Figures 7 (a1), $9(\mathrm{a} 1)$, and 9 (b1) that the strain of the specimens was relatively regular in a steady tension state. The increasing of the applied load leaded to the maximum strain occurring at the new-to-old concrete interface (Figures 7(a2), 9(a2), and 9(b2)). Those specimens showed the same behavior wherein the crack propagated at the interface, and the specimens end 

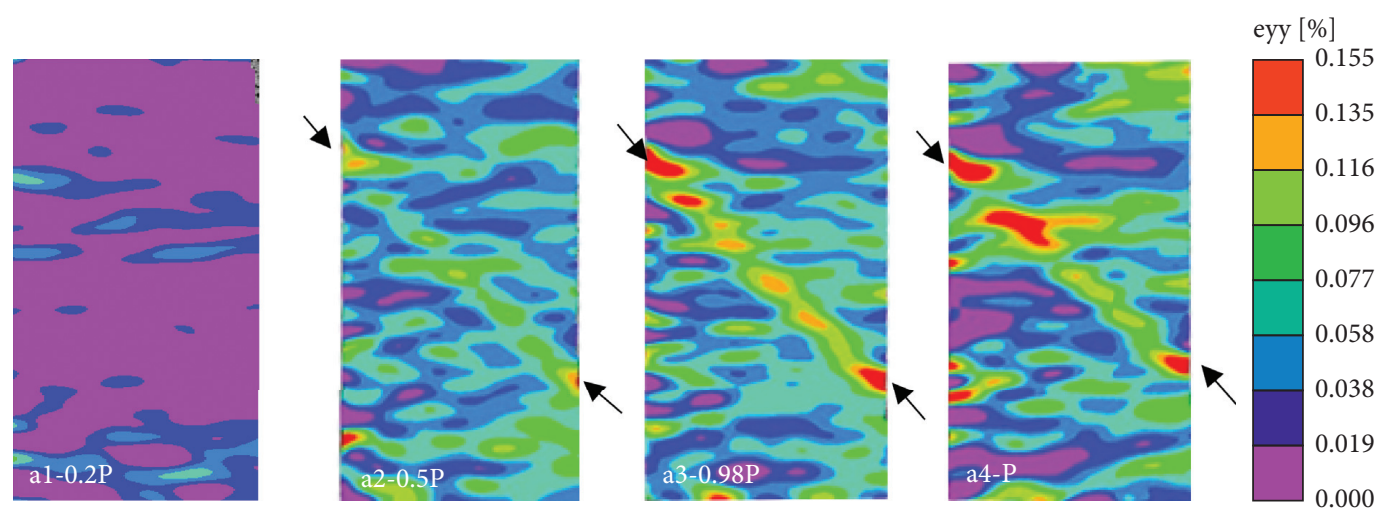

(a)
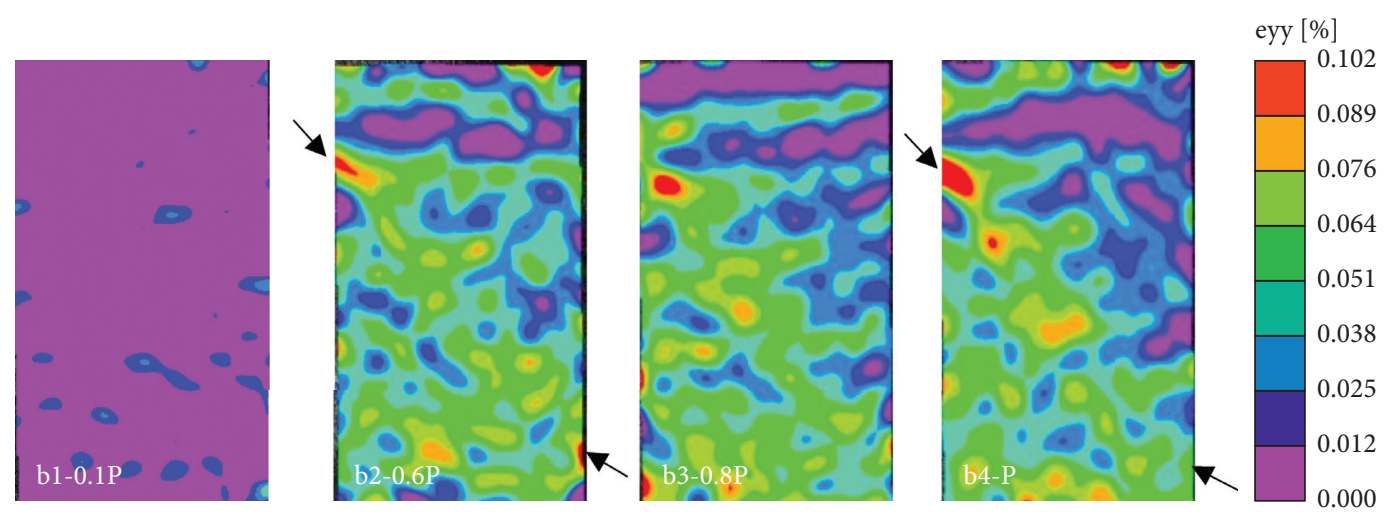

(b)
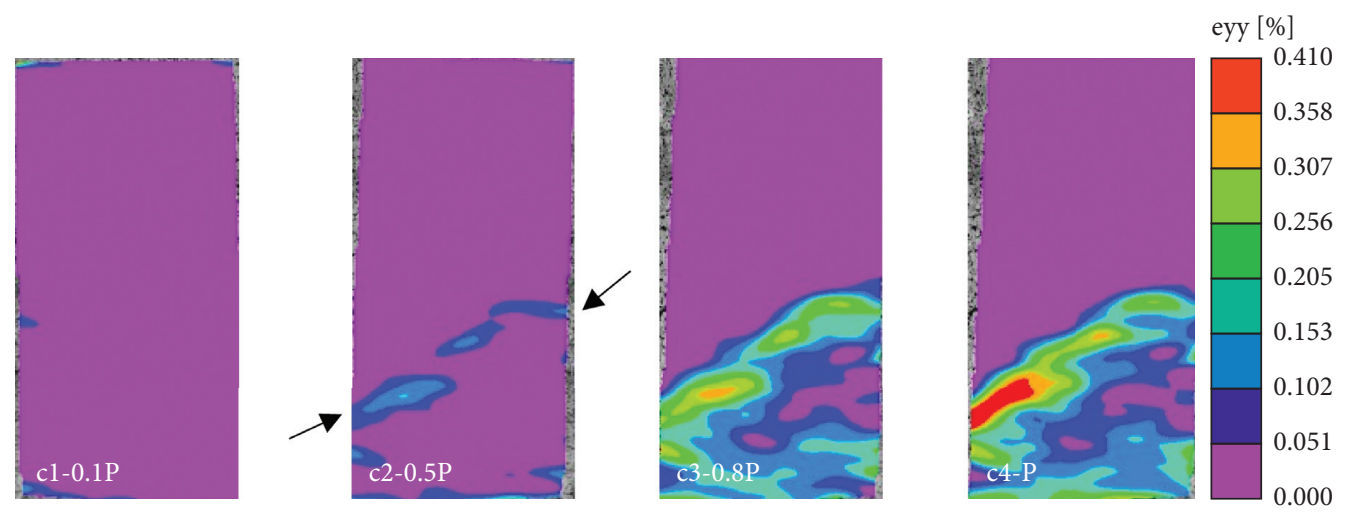

(c)

FIGURE 8: Vertical strain field for specimen with various surface treatment types at different loading stages: (a) C50-C50-WB-45 (primary surface), (b) C50-C50-MG-45 (primary surface), and (c) C50-C50-AC-45 (primary surface).

with full expansion of the crack with maximum strain value, as shown in Figures 7(a3), 9(a3), and 9(b3). It manifested that the increase of concrete compressive strength slightly improved the bond strength, wherein the increase was only $4.5 \%$ as the compressive strength of the new concrete part increased from 40 to $50 \mathrm{MPa}$. The crack development degree of low strength concrete was larger than the high strength concrete in terms of quantity, width, and length. Almost all specimen damage was initiated from microcracks at the edges of the specimen interface, which indicated that the specimen damage prediction can be estimated based on the development state of cracks.
3.3.4. Effect of Interfacial Angle. As presented in Figures 7(a2), 10(a1), and 10(b1), all specimens initialed to emerge stress concentration at the new-to-old surface, while there were fewer cracks in other locations (Figures 10(a2) and 10(b2). As the load increased (Figures 7(a3), 10(a3), and 10(b3)), the cracks propagated along the interface and approximately formed a connecting crack. Finally, the damage of those specimens was followed the interface, presenting a typical adhesive failure (Figures 7(a4), 10(a4), and 10(b4)).

From the variation in all specimen strain nephogram, the crack development could be divided into three stages: crack disorder development stage, major crack stress 


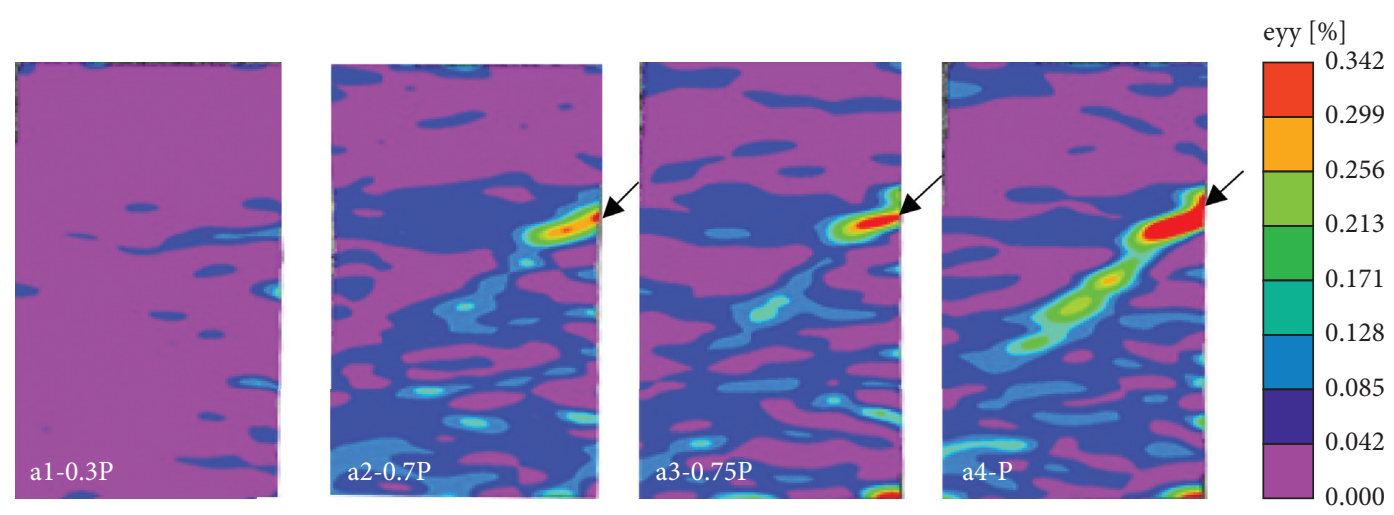

(a)
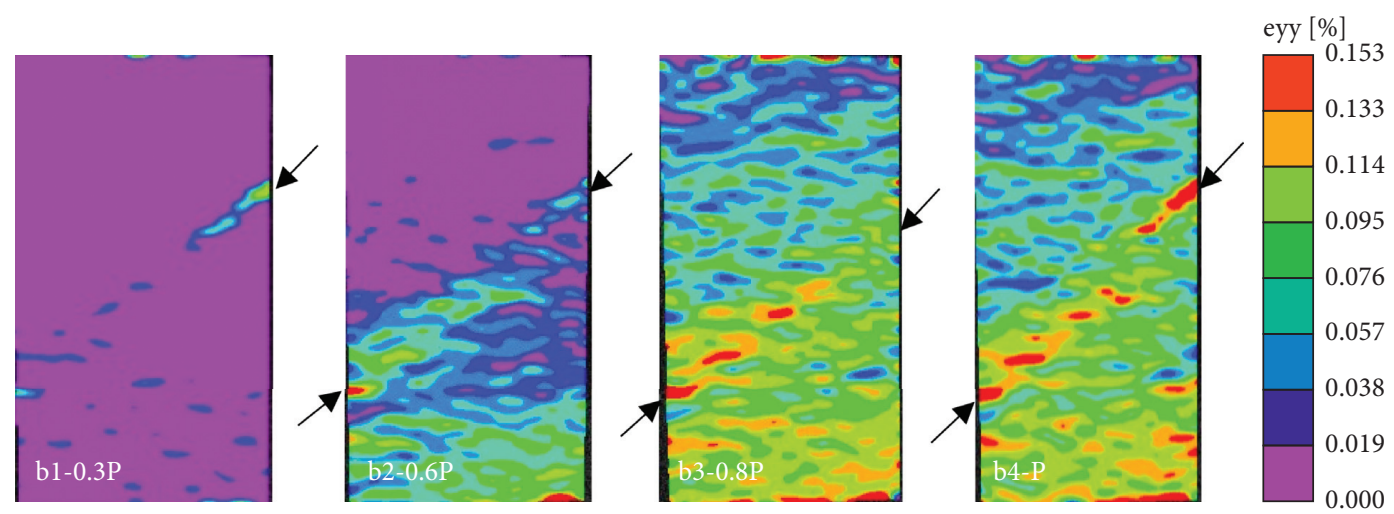

(b)

FIgURe 9: Vertical strain field for specimen with various new concrete strength grade at different loading stages: (a) C50-C40-BG-45 (primary surface) and (b) C50-C60-BG- $45^{\circ}$ (primary surface).

concentration stage, and specimen damage stage. (1) When the specimen was loaded at $0.3-0.5 \mathrm{P}$, numerous microcracks were formed on the surface, which were almost uniformly distributed on the specimen surface. (2) As the load increased $(0.5-0.8 \mathrm{P})$, the area where the concrete matrix has defects appeared with higher strain. It could be clearly observed that the strain increased faster, and the strain in other microcracks was also increasing in the meantime. At this stage, the structure damage location could be determined by the strain nephogram. If the structure is repaired at this stage, the structure can be prevented from being damaged while ensuring the structure's bearing capacity. (3) When the load reached $0.8-0.9 \mathrm{P}$, the major strain increased rapidly and enlarged a significant gap with the other regions, accompanied by a decrease in microcrack strains in other regions.

\subsection{Microstructure of New-to-Old Concrete}

3.4.1. Microstructure of Fiber-Reinforced Concrete. From Figure 11(a), it can be seen that the steel fiber with 100 microns diameter was extracted from the concrete matrix, and the surface of the pulled-out steel fiber exhibited strip texture. Besides, there was less hydration on the pulled-out fiber surface. It revealed that the steel fibers disturbed the surrounding concrete matrix and dissipate the energy when they were pulled out.
Figure 11(b) presents the polypropylene fibers with a diameter of 30 microns and a hilly surface texture. There was a gap between the fiber and the concrete matrix (Figure 11(c)), and many microcracks emerged in the concrete matrix around the fiber. Besides, small concrete fragments still connected the concrete matrix to the fiber surface, and some of the slurries were still attached to the polypropylene fibers owing to its rough surface. The phenomenon indicated that the polypropylene fiber has a rough surface and can be tightly attached to the concrete matrix while offering strong bond strength of the new-to-old concrete interface.

3.4.2. Interface Microstructure of New-to-Old Concrete. Furthermore, Figure 12 indicates that numerous hydration products of cementitious composites aggregated in the bond interface between new-to-old concrete, including ettringite (AFt) with a needle-like shape, calcium silicate hydrates (C$\mathrm{S}-\mathrm{H})$ with a honeycomb structure, and $\mathrm{Ca}(\mathrm{OH})^{2}$ crystal plates with six sides. Besides, it was distinct that the hydration products were inserted into, wrapped, and overlapped each other, including the following three type phenomena. (1) Figure 12(a) demonstrates that AFt crystals extended from the bilateral interface to the transition zone, and the crystals at the interface were dense compared with that of the transition zone. (2) It denoted that the C-S-H 

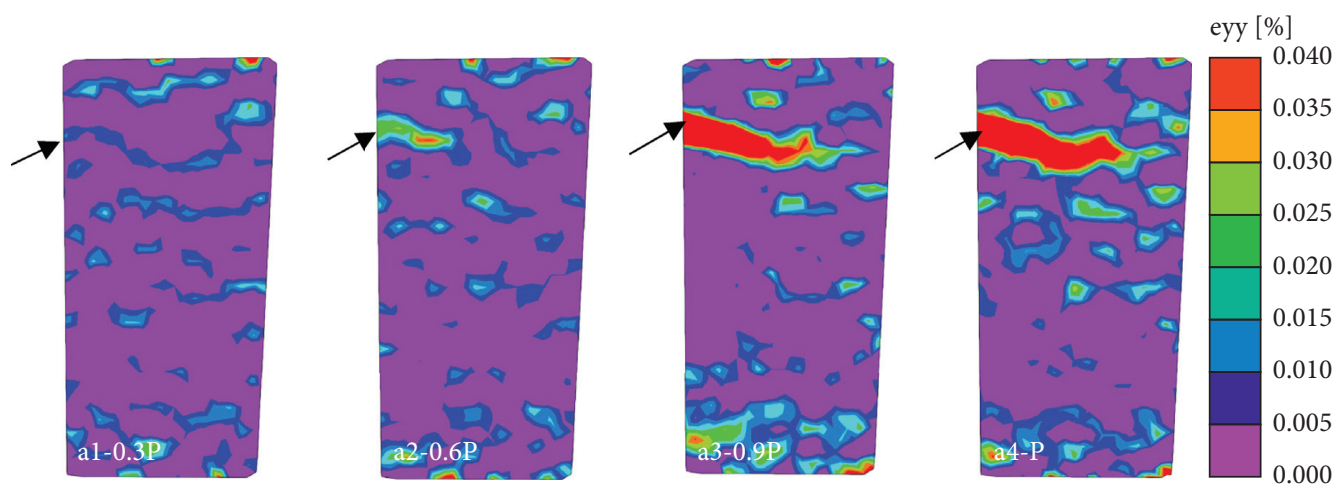

(a)
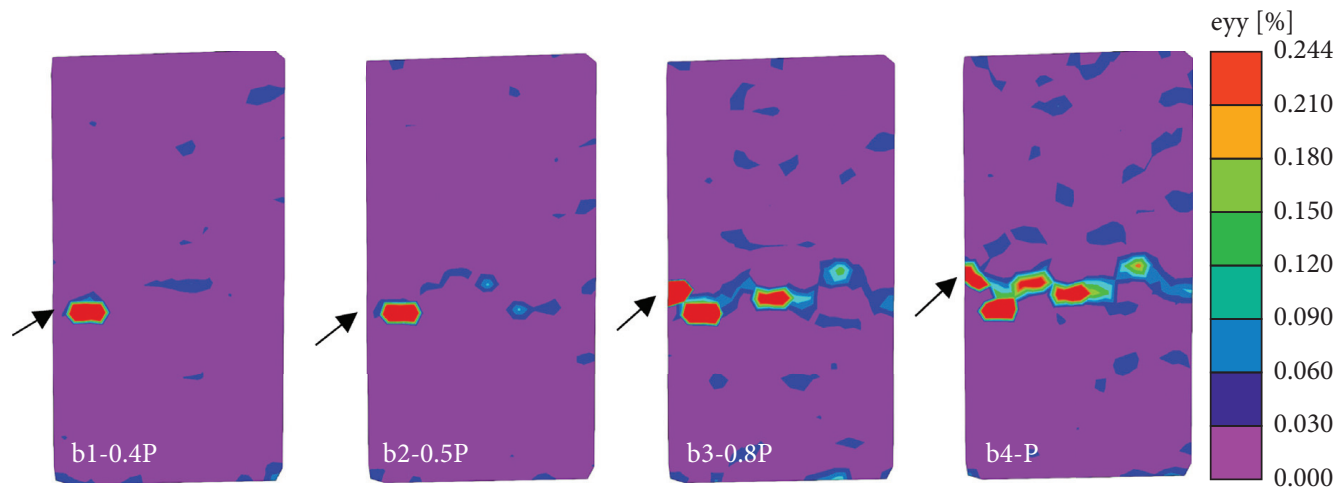

(b)

FIGURE 10: Vertical strain field for specimen with various interfacial angles at different loading stages. (a) C50-C50-BG-60 (side surface) and (b) C50-C50-BG-90 (primary surface).

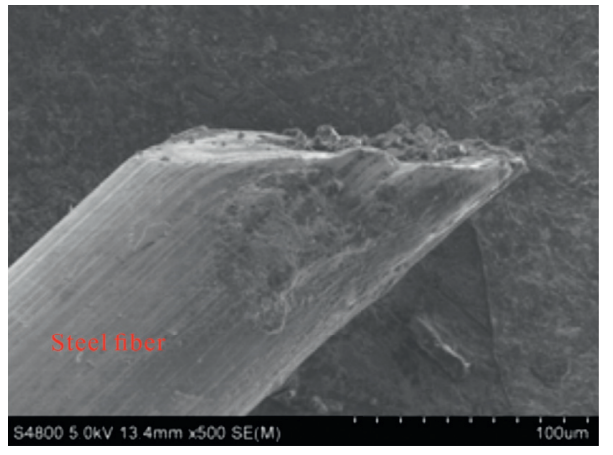

(a)

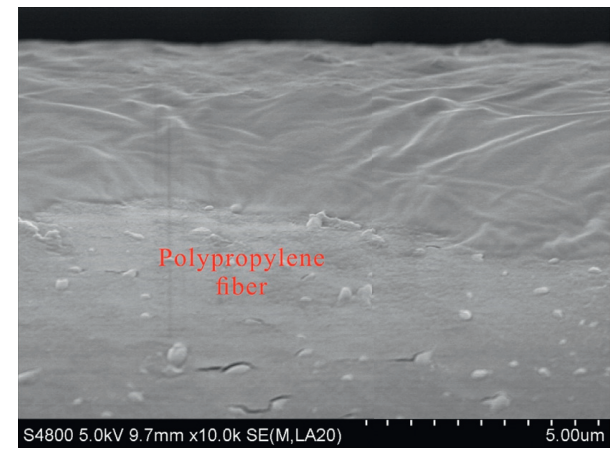

(b)

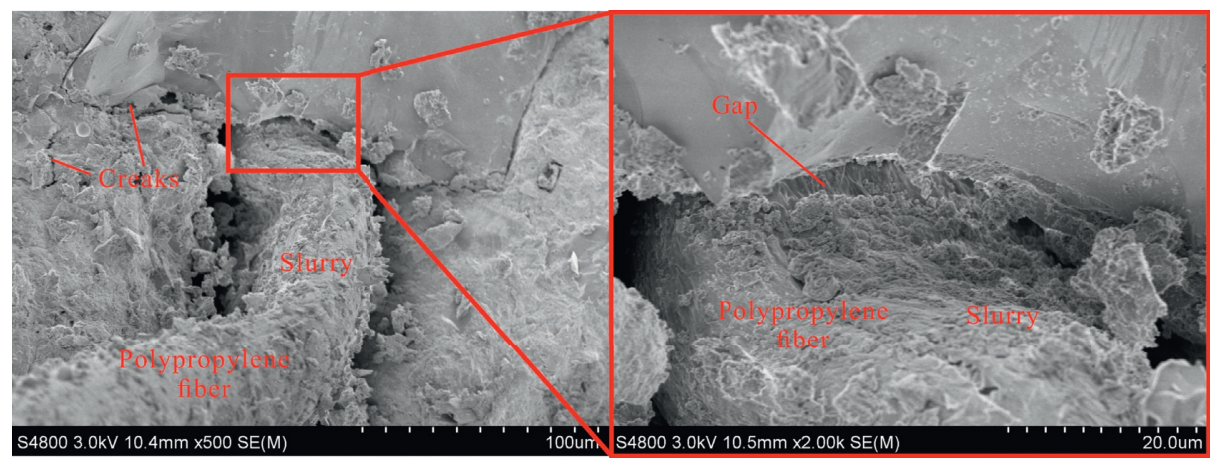

(c)

FIgURE 11: Microstructure of fiber-reinforced concrete. 


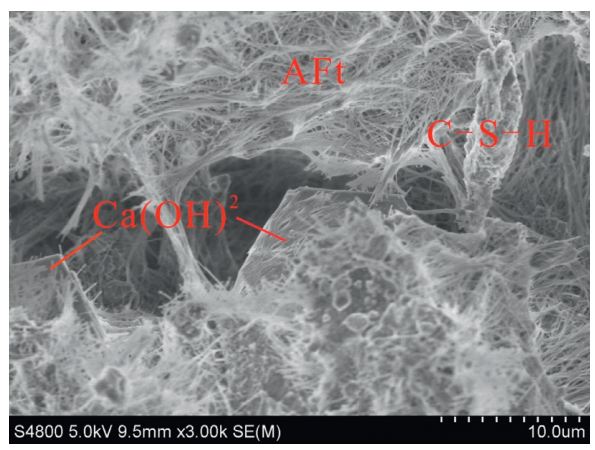

(a)

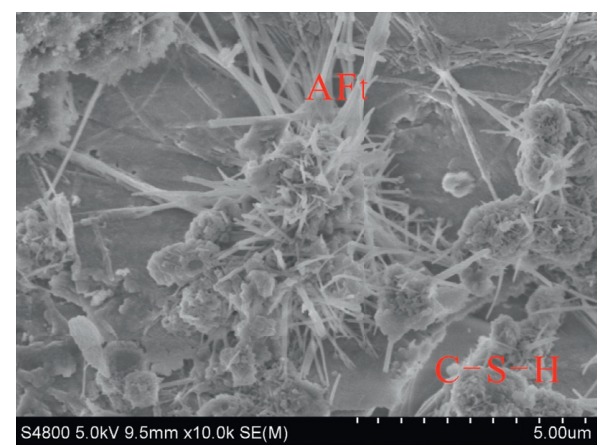

(b)

FIGURE 12: Micrograph of the bond interface between new and old concrete.

encapsulated some AFt, but some AFt passed through the $\mathrm{C}-\mathrm{S}-\mathrm{H}$ due to the special acicular shape of AFt crystals (Figure 12(b)), which demonstrated that C-S-H can fill the voids of AFt crystals to increase the density of the transition zone while offering strong bond strength. (3) It could be seen that the AFt crystals overlapped on both interfaces, were wrapped with $\mathrm{Ca}(\mathrm{OH})^{2}$ crystal plates (Figure $12(\mathrm{a})$ ), and were encased in $\mathrm{C}-\mathrm{S}-\mathrm{H}$ extending from the two sides to the transition zone. Although affluent crystals located in the bilateral interface were denser, there were few hydration products of cementitious composites in the transition zone to create more pores, which indicated that the bond zone between new-to-old concrete was still a weak area compared with the concrete matrix. The results were consistent with the conclusion of the 3D-DIC strain nephogram.

Based on the previous system analysis, there are various measures to improve the new-to-old concrete interface performance. As presented in Figure 1(a), the bond behavior of the new-to-old concrete between ordinary concretes is relatively vulnerable, which is suitable for the locations subjected to less force and vibrations in structure. As for the FRC as the old concrete (Figure 1(b)), the exposed part of the fibers can be cooperated with the new ordinary concrete after the FRC interface treatment, forming a fiber-reinforced concrete transition zone. This effectively compensates for the deficiencies in interface bond behavior, including the uneven shrinkage between old and new concrete, more holes and crystals at the interface. This type interface is appropriate for the vital parts of the structure, which are prone to force concentration and more vibrations, such as bridges and long-span structures. The Sandwich interface shown in Figure 1(c) is a refinement in terms of the FRC as old concrete, which was beneficial to introduce only a small amount of FRC at the old concrete interface to achieve the effect of fiber reinforcement. The implementation of this method is to pour a part of FRC in the interface location after the old concrete is poured. The Sandwich interface effectively avoids extensive using of expensive fibers and difficulty in manufacturing large-volume FRC, which can be widely employed in prefabricated, bridge structures, and viaduct structures. Furthermore, improving new concrete strength, interface area and roughness can also enhance the bond strength, wherein the interface roughness has a significant impact. The surface treated by AC and WG produced better bond behavior with new concrete compared to BG and MG. The AC and WG can be utilized to process the ordinary concrete surface, which use electric tools and are suitable for large surface. In case of FRC surface, it is a good choice to adopt the WG because the iron brush is less destructive to fibers.

\section{Experimental Analysis}

185 databases for new-to-old concrete tensile bond strength $[4,17,18,32,50-52]$ were collected from literatures as shown in Figure 13. The multifactor formula for calculating the bond strength between the new-to-old concrete was established based on the formula for calculating the bond strength of [53] $\left(\mathrm{fctm}=0.19 f_{\mathrm{cub}}^{3 / 4}\right)$ and massive databases. This was mainly attributed that the coefficient of variation between the test data and calculated data by fctm $=0.19 f_{\mathrm{cub}}^{3 / 4}$ was $167 \%$ (Figure 13(a)), which was far more than $15 \%$. Furthermore, the mean, median, and mode values of the test to calculated data ratio were $0.39,0.34$, and 0.33 , respectively. Hence, the influence factors in terms of the concrete strength, interfacial angle, fibers, and interfacial roughness were considered:

$$
f_{B T}=0.00419 \mathrm{f}_{\mathrm{cub}}^{3 / 4} \cdot \alpha \cdot \frac{(\mu+15.73979)}{\sin \theta},
$$

where $f_{B T}$ refers to tensile bond strength between the new-toold concrete. $\alpha$ is the influence coefficient of fiber addition. The value of this factor is 1 when the old concrete is the common concrete, while the factors are 2.26 and 1.33 for the old concrete when the steel fiber and polypropylene fiber volume fraction are $0.25 \%$, respectively. Besides, the factor is 1.55 for the old hybrid fiber-reinforced concrete with $0.125 \%$ steel fiber and $0.125 \%$ polypropylene fiber volume fraction. $\mu$ refers to the interfacial roughness. $f_{c u b}$ denotes the cube compressive strength of the new concrete. $\theta$ is the angle between the interface and the longitudinal direction of the specimen.

From Figure13(b), the standard deviation between the test data and calculated data by formula (3) was 0.06 , and the correlation coefficient $R^{2}$ and adjustment correlation coefficient $R^{2}$ were 0.80 and 0.80 , respectively. Besides, the mean, 


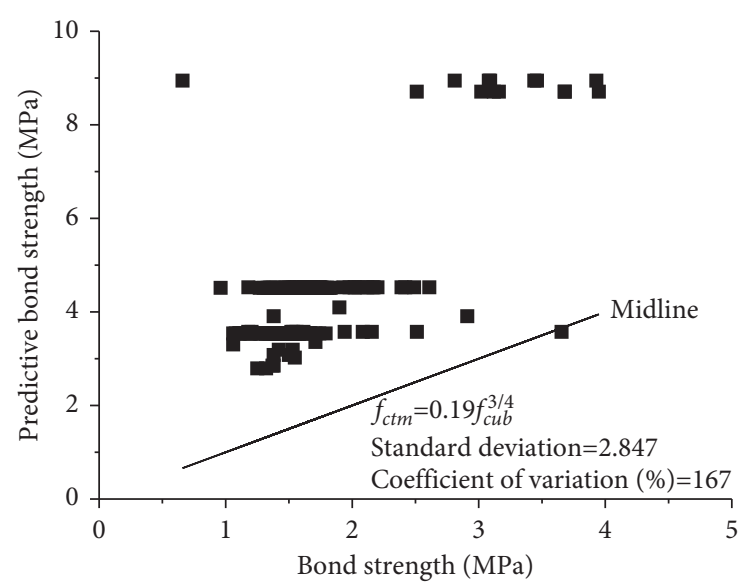

- Test data

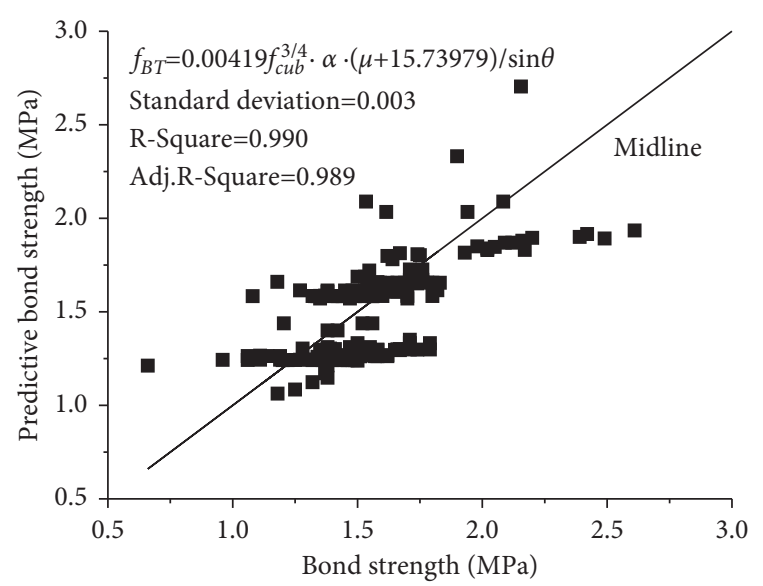

- Test data

(a)

(b)

FIGURE 13: Comparison of experimental values and predictions.

median, and mode values of the test to calculated data ratio were $1.01,0.97$ and 1.15 , respectively. This indicated that the test data was in good agreement with the calculated data by formula (3). The formula can be used to evaluate the axial tensile strength of the new-to-old interface in engineering.

\section{Machine Learning Model Training and Results}

In case of single weak learner, it is sensitive to training data and inclined to overfitting, while the ensemble machine learning method can be able to figure out these issues $[54,55]$. Ensemble methods combine the decisions of multiple machine learning models to improve the overall model performance due to its excellent generalization performance and prediction in civil engineering, which has been proven in various studies $[43,56-58]$. The workflow of the ensemble machine learning model is presented in Figure 14.

5.1. Experimental Database. The database contained 185 test samples of new-to-old concrete tensile bond strength $[4,17,18,32,50-52]$. The characteristic parameters included new concrete compressive strength, old concrete compressive strength, interfacial roughness, and tensile bond strength, which were also employed as research objectives. Table 6 presents the frequency distribution of the various characteristic parameters in the collected experimental database. The Kernel Density Estimation (KDE) of the characteristic parameters are shown in Figure 15, wherein the blue curve represented the KDE and the dashed line denoted the data average value. It could be seen that the characteristic parameters approximately obeyed a normal distribution, which indicated that the collected experimental data were well distributed and could be the estimated sample for the machine learning method. This paper employed the random sampling method to divide the database into training and test datasets at a ratio of $7: 3$.
5.2. Evaluation of the Model Performance. Four typical measure methods in machine learning method are adopted to evaluate the model performance as the quantitative metric, and the four measure methods are defined as follows:

(1) Coefficient of determination R-squared $\left(R^{2}\right)$ is as follows:

$$
R^{2}=1-\frac{\sum_{i=1}^{m}\left(P_{i}-T_{i}\right)^{2}}{\sum_{i=1}^{m}\left(P_{i}-\bar{T}\right)^{2}}
$$

(2) Root mean squared error (RMSE) is as follows:

$$
\mathrm{RMSE}=\sqrt{\frac{\sum_{i=1}^{m}\left(P_{i}-T_{i}\right)^{2}}{m} .}
$$

(3) Mean absolute error (MAE) is as follows:

$$
\text { MAE }=\frac{\sum_{i=1}^{m}\left|P_{i}-T_{i}\right|}{m} .
$$

(4) Mean absolute percentage error (MAPE) is as follows:

$$
\mathrm{MAPE}=\frac{100 \%}{m} \sum_{i=1}^{m}\left|\frac{P_{i}-T_{i}}{T_{i}}\right|,
$$

where $T_{\mathrm{i}}$ and $P_{i}$ are the test and prediction value. $i(1,2,3, \ldots, m)$ refers to the sample number. If the RMSE, MAE, and MAPE values are smaller and the $R^{2}$ value is larger, the model prediction will be more accurate.

5.3. Bond Strength Prediction. To obtain the model for predicting the tensile bond strength of new-to-old concrete interface, 16 types of ensemble machine learning models (Table 7) were employed, wherein the 10 -fold cross validation was adopted to evaluate those model performances based on 185 test data. Moreover, the calculation parameters 


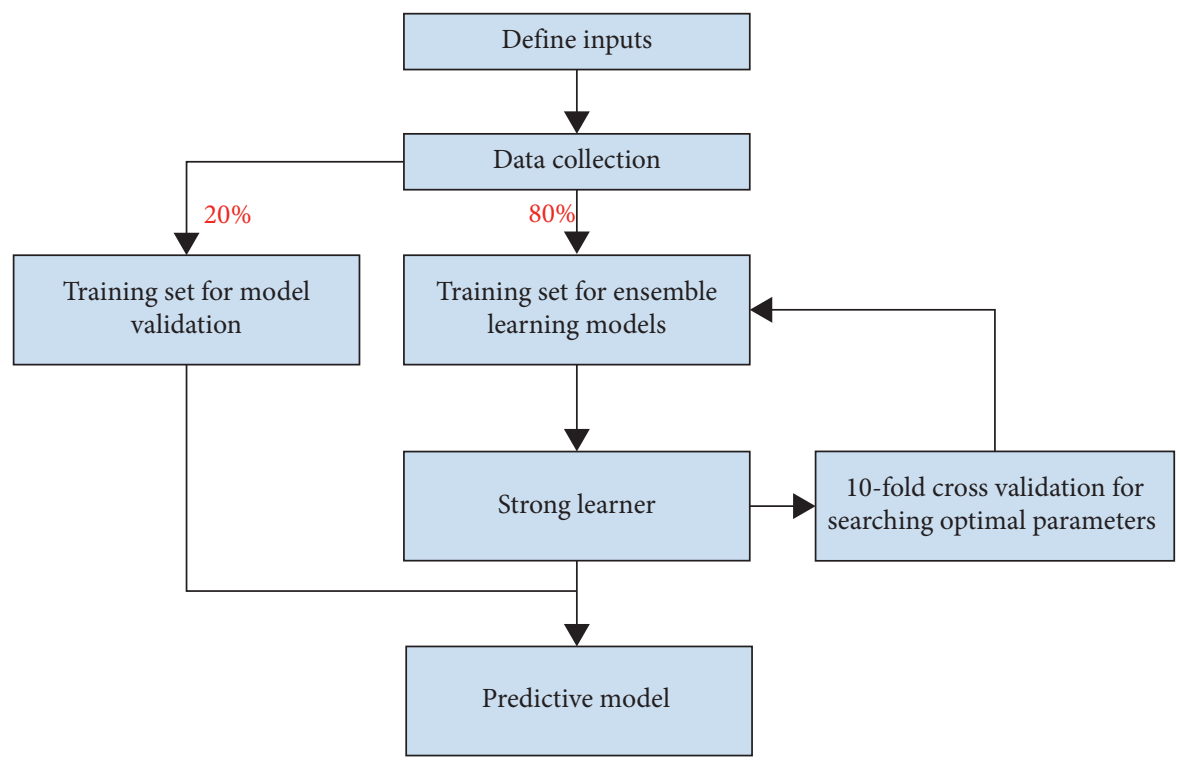

FIGURE 14: Workflow of the ensemble machine learning model.

TABLE 6: Statistical information of parameters included 185 experimental data.

\begin{tabular}{|c|c|c|c|c|c|c|c|c|}
\hline Factor & Number & Mean & Standard & Min & $25 \%$ & $50 \%$ & $75 \%$ & Maximum \\
\hline New concrete strength & 185 & 66.52 & 30.47 & 36.00 & 49.37 & 68.29 & 68.29 & 170.00 \\
\hline Old concrete strength & 185 & 49.80 & 7.94 & 32.75 & 44.71 & 48.41 & 52.47 & 68.50 \\
\hline Roughness & 185 & 1.01 & 0.95 & 0.16 & 0.39 & 0.50 & 1.5 & 3.64 \\
\hline Bond strength & 185 & 1.69 & 0.56 & 0.66 & 1.40 & 1.54 & 1.71 & 3.95 \\
\hline
\end{tabular}

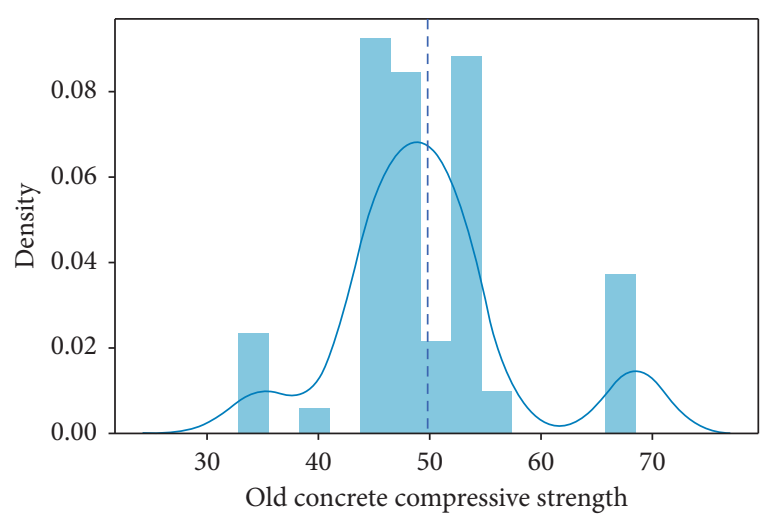

(a)

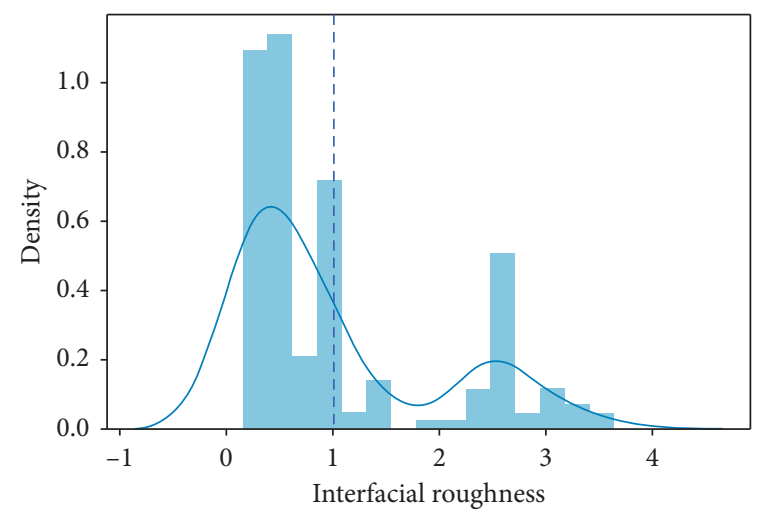

(c)

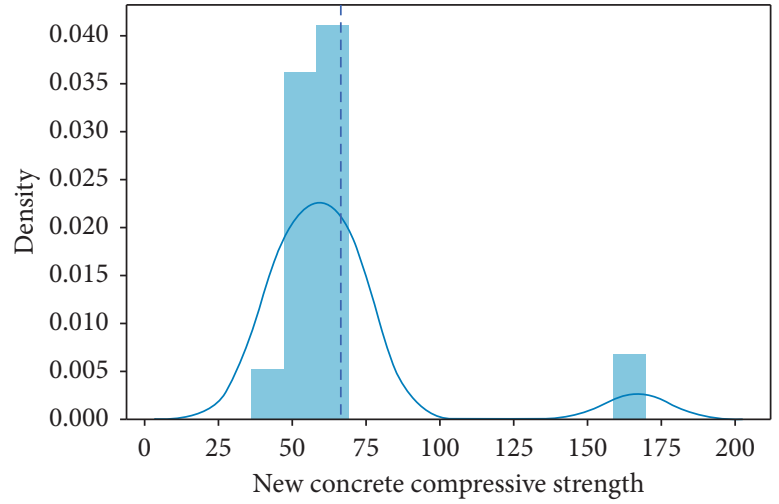

(b)

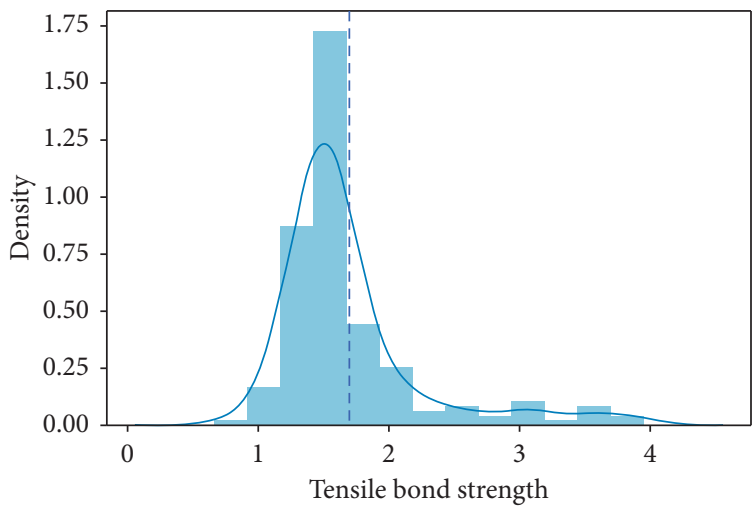

(d)

FIGURE 15: Statistical distributions of the experimental data. 
Table 7: Performance measures.

\begin{tabular}{lcc}
\hline Regression models & $R^{2}$ & RMSE (kN) \\
\hline Linear regression & 0.75 & 0.16 \\
Linear regression degree 2 & 0.77 & 0.16 \\
Linear regression degree 3 & 0.32 & 0.17 \\
Ridge & 0.79 & 0.17 \\
Ridge degree 2 & 0.79 & 0.16 \\
Ridge degree 3 & 0.71 & 0.15 \\
Lasso & -0.07 & 0.35 \\
Lasso degree 2 & 0.22 & 0.31 \\
Lasso degree 3 & 0.49 & 0.23 \\
Decision tree & 0.81 & 0.14 \\
Ada boosting & 0.74 \\
Random Forest & 0.74 & 0.17 \\
Gradient boosting & 0.81 & 0.17 \\
KNN & 0.80 & 0.14 \\
XGBoost & 0.82 & 0.15 \\
SVR & 0.80 & 0.14 \\
Best model = XGBoost & 0.83 & 0.15 \\
\hline
\end{tabular}

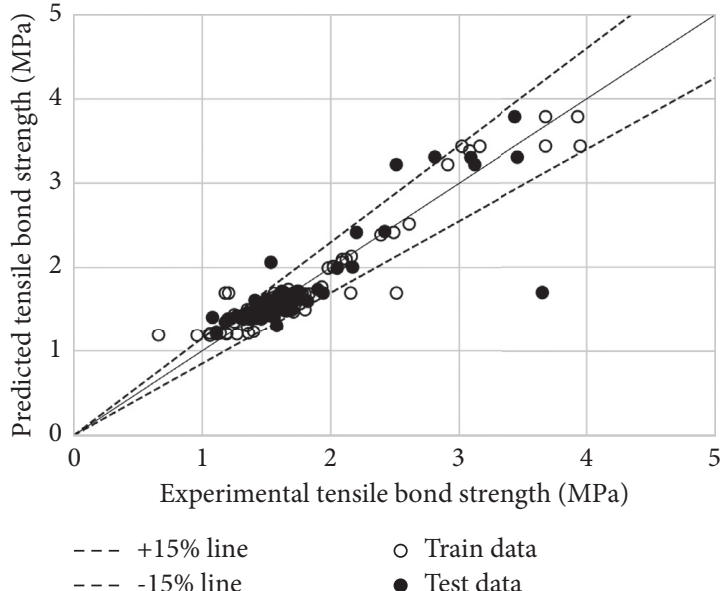

(a)

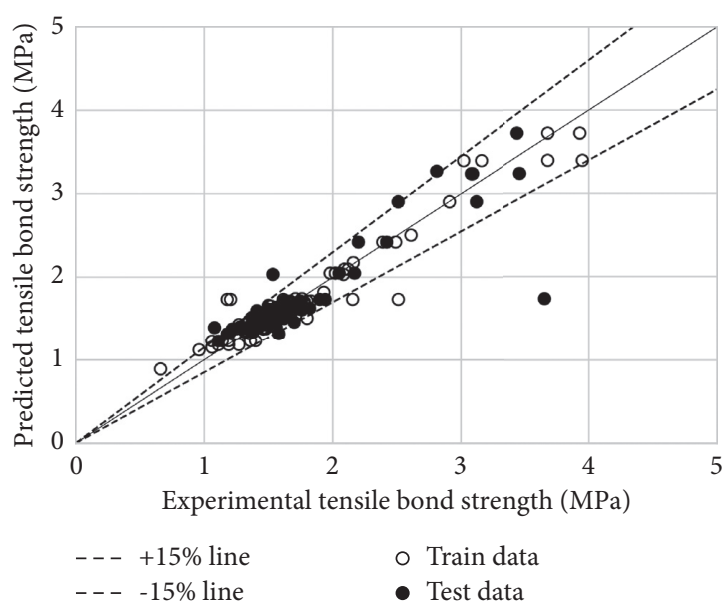

(c)

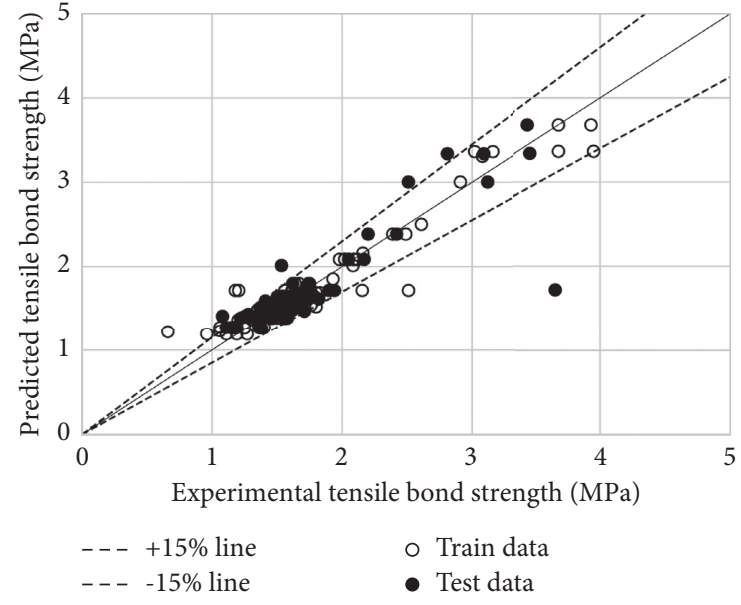

(b)

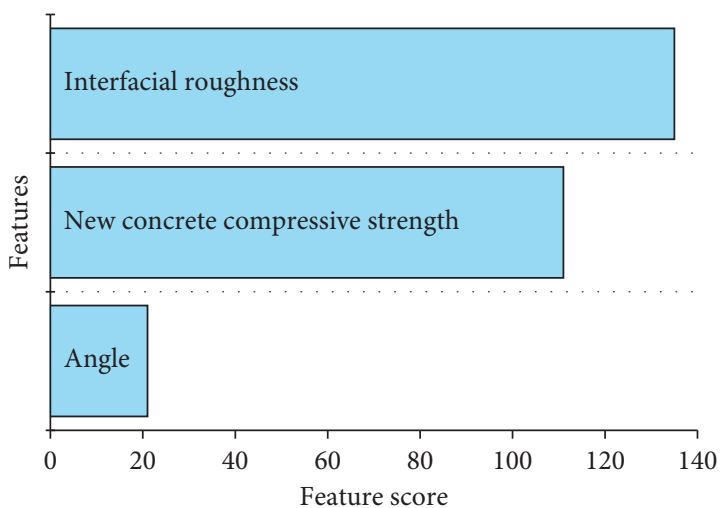

(d)

FIGURE 16: Predicted performance. (a) Random Forest model. (b) Gradient boosting model. (c) XGBoost model. (d) Feature importance. 
of the machine learning method were default values, and performance measures for those models are listed in Table 7. The Lasso regression algorithms had the lowest prediction accuracy, and the $R^{2}$ was mostly low. Moreover, the XGBoost models achieved the highest $R^{2}(0.8)$, which indicated that those models can be adopt to predict precise results.

The XGBoost, Random Forest, and Gradient boosting models were adopted as the prediction model for further training. Afterwards, the optimal parameters were selected by 10 -folds cross validation and Grid search methods based on the test dataset. The model prediction results and metric parameters are shown in Figure 16 and Table 8. These three models whole performed well. For instance, the training dataset $R^{2}$ of XGBoost model reached the 0.92 , and other performance metrices, including RMSE $(0.15 \mathrm{kN})$, MAE $(0.09 \mathrm{kN})$, and MAPE $(5.85 \%)$, were low. Moreover, the test dataset performances $\left(R^{2}=0.73, \quad \mathrm{RMSE}=0.30 \mathrm{kN}\right.$, $\mathrm{MAE}=0.16 \mathrm{kN}$, and $\mathrm{MAPE}=7.92 \%$ ) were low and mainly attributed to an outlier caused by experimental error. Fortunately, almost all sample errors were less than $15 \%$. This indicated that The XGBoost, Random Forest, and Gradient boosting models can be used to accurately and efficiently predict the tensile bond strength of new-to-old concrete in engineering. In general, due to the limited experimental data samples, the XGBoost model cannot reflect all situations involving bond strength in the engineering. Therefore, the application scope of the parameter analysis conclusions in this paper is as follows. The range of new concrete compress strength is $25.87-170 \mathrm{kN}$, the range of old concrete compress strength is $22.32-73.2 \mathrm{kN}$, and the roughness is $0-3.64 \mathrm{~mm}$.

This paper conducted feature importance analysis on the machine learning model (XGBoost), as presented in Figure 16(d). The results indicated that the effectors of interfacial roughness and new concrete lightness had a significant impact on the interface bond strength and were higher than the interface angle. This phenomenon was consistent with the conclusions of the current researches $[4,17,18,23,26,32,50-52]$, which indicated that the machine learning model employed in this paper was identified with the existing expert experience $[1,14,15,17,18,26,31,33,41,50,51,59]$.

The XGBoost model $R^{2}(0.92)$ was higher than that of formula (3), while it employed only three influence parameters. This demonstrated that the machine learning models were characterized with lower prediction error and higher generalization capacity, while offering accurate and rapid predictions. Considering that the mechanics-driven method reveals mechanism and behavior interpretation, it was vital that the development of ML-based methods should not reduce the importance of the mechanics-driven methods. In fact, these two series of methods form a more comprehensive and complete approaches, wherein these two methods complement to each other and can obtain seamless services in structural analysis and design. Hence, it is fundamental to combine the two methods for better engineering application. When there is no available theoretical formula, machine learning can be applied for preliminary predictions.
TABle 8: Performance measures for the XGBoost, Gradient boosting, and Random Forest model.

\begin{tabular}{lccccc}
\hline $\begin{array}{l}\text { Regression } \\
\text { models }\end{array}$ & Sets & $R^{2}$ & RMSE (kN) & MAE (kN) & MAPE (\%) \\
\hline Random & Test & 0.70 & 0.32 & 0.17 & 8.48 \\
Forest & Train & 0.91 & 0.16 & 0.10 & 6.55 \\
Gradient & Test & 0.72 & 0.31 & 0.16 & 8.08 \\
boosting & Train & 0.90 & 0.16 & 0.11 & 6.90 \\
XGBoost & Test & 0.73 & 0.30 & 0.15 & 7.91 \\
& Train & 0.92 & 0.15 & 0.10 & 5.85 \\
\hline
\end{tabular}

\section{Conclusions}

The following conclusions can be drawn:

(1) The specimen failure modes were subdivided into 3 categories: adhesive failure, partial adhesive failure, and cohesive failure. Adhesive failure has been identified as one of the most common failure modes of the new-to-old concrete specimen. Moreover, the specimens cooperating with steel and polypropylene fiber were more likely to generate partial adhesive failure or cohesive failure.

(2) The axial tensile bond behavior between new-to-old concrete was significantly promoted by cooperating with the steel and polypropylene fiber, interfacial angle, and surface treatment type. In addition, the axial tensile bond strength reached its maximum when the specimen cooperated with a $0.25 \%$ steel fiber volume fraction. It was an excellent choice to only introduce fibers in the old concrete at the interface area to enhance the bond strength of the newto-old concrete interface.

(3) The location of maximum strain obtained from DIC was the same as the location of the failure of the specimens. This indicated the effectiveness of adopting the DIC technique to monitor and forecast the behavior of concrete structures. The strain of the microcracks located in the major crack was decreased with the development of the major crack, and the further away from the major crack, the more obvious the stress reduction.

(4) The surface of the polypropylene fiber was rough and easy to attach with the concrete matrix. Nevertheless, the surface of the steel fiber was very smooth, and the steel fiber tended to pull out from the concrete matrix.

(5) Affluent crystals and $\mathrm{Ca}(\mathrm{OH})^{2}$ crystal plates have emerged in the interface between the new-to-old concrete, as well as more pores. The interface area was the weak area compared with the concrete matrix corresponding to the maximum strain nephogram of the DIC. Therefore, it was necessary to adopt the various methods, such adding fibers, choosing surface treatment method, increasing the new concrete strength, and adjusting the interfacial angle to improve the bond behavior of the new-toold concrete interface. 
(6) The formula for calculating axial tensile bond strength within the new-to-old concrete was established based on 185 databases. Moreover, the XGBoost model could be employed to accurately and effectively predict the bond strength. The calculated values were consistent with the experimental values and can be used in practical projects as a preliminary prediction.

\section{Data Availability}

The data that support the findings of this study are available from the corresponding author (15029287701@163.com).

\section{Conflicts of Interest}

The authors declare that there are no conflicts of interest regarding the publication of this study.

\section{Acknowledgments}

The work described in this paper was supported by the National Natural Science Foundation of China (no. 51778060), the Natural Science Foundation of Shaanxi Province (no. 2020KW-067), the Natural Science Foundation of Jiangsu Province (no. BK20191441), and the Fundamental Research Funds for the Central Universities, CHD (nos. 300102289401, 300102280711, and 300102280713).

\section{References}

[1] D. P. Bentz, I. De la Varga, and J. F. Muñoz, "Influence of substrate moisture state and roughness on interface microstructure and bond strength: slant shear vs. Pull-off testing," Cement and Concrete Composites, vol. 87, pp. 63-72, 2018.

[2] E. N. B. S. Júlio, F. A. B. Branco, and V. T. D. Silva, "Concreteto-concrete bond strength. Influence of the roughness of the substrate surface," Construction and Building Materials, vol. 18, no. 9, pp. 675-681, 2004.

[3] J. Qin, J. Qian, C. You, Y. Fan, Z. Li, and H. Wang, "Bond behavior and interfacial micro-characteristics of magnesium phosphate cement onto old concrete substrate," Construction and Building Materials, vol. 167, pp. 166-176, 2018.

[4] A. A. Semendary and D. Svecova, "Factors affecting bond between precast concrete and cast in place ultra high performance concrete (UHPC)," Engineering Structures, vol. 216, 2020.

[5] A. Cascardi, M. Lerna, F. Micelli, and M. A. Aiello, "Discontinuous FRP-confinement of masonry columns," Frontiers in Built Environment, vol. 5, 2020.

[6] D. Foti, "On the numerical and experimental strengthening assessment of tufa masonry with FRP," Mechanics of Advanced Materials and Structures, vol. 20, no. 2, pp. 163-175, 2013.

[7] D. Foti and S. Vacca, "Comportamiento mecánico de columnas de hormigón armado reforzadas con mortero reoplástico," Materiales de Construcción, vol. 63, no. 310, pp. 267-282, 2012.

[8] M. Lerna, F. Micelli, A. Cascardi, and A. A. Maria, "Discontinuous CFRP-jacketing of masonry columns," Key Engineering Materials, vol. 817, pp. 398-403, 2019.
[9] S. Gao, J. Jin, G. Hu, and L. Qu, "Experimental investigation of the interface bond properties between SHCC and concrete under sulfate attack," Construction and Building Materials, vol. 217, pp. 651-663, 2019.

[10] E. N. B. S. Júlio, F. A. B. Branco, and V. D. Silva, "Concrete-toconcrete bond strength. Influence of the roughness of the substrate surface," Construction and Building Materials, vol. 18 , no. 9, p. 6, 2004.

[11] C. Thongchom, A. Lenwari, and R. S. Aboutaha, "Bond properties between carbon fibre-reinforced polymer plate and fire-damaged concrete," International Journal of Adhesion and Adhesives, vol. 97, 2020.

[12] J.-Y. Jia and X.-L. Gu, "Effects of coarse aggregate surface morphology on aggregate-mortar interface strength and mechanical properties of concrete," Construction and Building Materials, vol. 294, 2021.

[13] G. Mazzucco, V. A. Salomoni, and C. Majorana, “A cohesive contact algorithm to evaluate the mechanical behaviour of concrete ITZ at different roughness conditions," Construction and Building Materials, vol. 294, 2021.

[14] T. Oh, I. You, N. Banthia, and D. Y. Yoo, "Deposition of nanosilica particles on fiber surface for improving interfacial bond and tensile performances of ultra-high-performance fiber-reinforced concrete," Composites Part B: Engineering, vol. 221, 2021.

[15] H. Qiu, F. Wang, Z. Zhu et al., "Study on dynamic fracture behaviour and fracture toughness in rock-mortar interface under impact load," Composite Structures, vol. 271, 2021.

[16] H. Costa, R. N. F. Carmo, and E. Júlio, "Influence of lightweight aggregates concrete on the bond strength of concreteto-concrete interfaces," Construction and Building Materials, vol. 180, pp. 519-530, 2018.

[17] K. Gadri and A. Guettala, "Evaluation of bond strength between sand concrete as new repair material and ordinary concrete substrate (The surface roughness effect)," Construction and Building Materials, vol. 157, pp. 1133-1144, 2017.

[18] Y. He, X. Zhang, R. D. Hooton, and Z. Xiaowei, "Effects of interface roughness and interface adhesion on new-to-old concrete bonding," Construction and Building Materials, vol. 151, pp. 582-590, 2017.

[19] A. Momayez, M. R. Ehsani, A. A. Ramezanianpour, and H. Rajaie, "Comparison of methods for evaluating bond strength between concrete substrate and repair materials," Cement and Concrete Research, vol. 35, no. 4, pp. 748-757, 2005.

[20] B. A. Tayeh, B. H. Abu Bakar, and M. A. Megat Johari, "Characterization of the interfacial bond between old concrete substrate and ultra high performance fiber concrete repair composite," Materials and Structures, vol. 46, no. 5, pp. 743-753, 2012.

[21] B. A. Tayeh, B. H. Abu Bakar, M. A. Megat Johari, and L. V. Yen, "Mechanical and permeability properties of the interface between normal concrete substrate and ultra high performance fiber concrete overlay," Construction and Building Materials, vol. 36, pp. 538-548, 2012.

[22] M. A. Yazdi, E. Dejager, M. Debraekeleer, G. Elke, V. T. Kim, and D. B. Nele, "Bond strength between concrete and repair mortar and its relation with concrete removal techniques and substrate composition," Construction and Building Materials, vol. 230, 2020.

[23] S. H. Abo Sabah, M. H. Hassan, N. Muhamad Bunnori, and M. A. Megat Johari, "Bond strength of the interface between normal concrete substrate and GUSMRC repair material 
overlay," Construction and Building Materials, vol. 216, pp. 261-271, 2019.

[24] H. Fang, Z. Su, X. Li, W. Fuming, and Fu Yingchun, "Interfacial bond performance between self-expansion polymer and concrete," Construction and Building Materials, vol. 270, 2021.

[25] B. Hu, T.-F. Meng, Y. Li, D.-Z. Li, and L. Chen, "Dynamic splitting tensile bond behavior of new-to-old concrete interfaces," Construction and Building Materials, vol. 281, 2021.

[26] S. Feng, H. Xiao, and H. Li, "Comparative studies of the effect of ultrahigh-performance concrete and normal concrete as repair materials on interfacial bond properties and microstructure," Engineering Structures, vol. 222, 2020.

[27] M. Kuroda, T. Watanabe, and N. Terashi, "Increase of bond strength at interfacial transition zone by the use of fly ash," Cement and Concrete Research, vol. 2000, p. 5, 2000.

[28] G. Xiong, J. Liu, G. Li, and X. Huicai, "A way for improving interfacial transition zone between concrete substrate and repair materials," Cement and Concrete Research, vol. 2002, p. $4,2002$.

[29] G. Li, "A new way to increase the long-term bond strength of new-to-old concrete by the use of fly ash," Cement and Concrete Research, vol. 33, no. 6, pp. 799-806, 2003.

[30] M. Mohammadi, R. Mir Moghtadaei, and N. Ashraf Samani, "Influence of silica fume and metakaolin with two different types of interfacial adhesives on the bond strength of repaired concrete," Construction and Building Materials, vol. 51, pp. 141-150, 2014.

[31] E. Bonaldo, J. A. O. Barros, and P. B. Lourenço, "Bond characterization between concrete substrate and repairing SFRC using pull-off testing," International Journal of Adhesion and Adhesives, vol. 25, no. 6, pp. 463-474, 2005.

[32] V. A. Nunes, P. H. R. Borges, and C. Zanotti, "Mechanical compatibility and adhesion between alkali-activated repair mortars and Portland cement concrete substrate," Construction and Building Materials, vol. 215, pp. 569-581, 2019.

[33] K. Rashid, M. Ahmad, T. Ueda et al., "Experimental investigation of the bond strength between new to old concrete using different adhesive layers," Construction and Building Materials, vol. 249, 2020.

[34] J. A. Wells, R. D. Stark, and D. Polyzois, "Getting better bond inconcrete overlays," Concrete International, vol. 21, no. 3, pp. 49-52, 1999.

[35] E. K. Tschegg, M. Ingruber, and C. H. Surberg, "Factors influencing fracture behavior of old-new concrete bonds," ACI Materials Journal, vol. 97, no. 4, pp. 447-453, 2000.

[36] A. H. C. Shin and D. A. Lange, "Effects of overlay thickness on surface cracking and debonding in bonded concrete overlays," Canadian Journal of Civil Engineering, vol. 39, no. 3, pp. 304-312, 2012.

[37] S. Xu, F. Mu, J. Wang, and Li Weiping, "Experimental study on the interfacial bonding behaviors between sprayed UHTCC and concrete substrate," Construction and Building Materials, vol. 195, pp. 638-649, 2019.

[38] H. Huang, Y. Yuan, W. Zhang, and G. Zichen, "Bond behavior between lightweight aggregate concrete and normal weight concrete based on splitting-tensile test," Construction and Building Materials, vol. 209, pp. 306-314, 2019.

[39] C. Zanotti, N. Banthia, and G. Plizzari, "A study of some factors affecting bond in cementitious fiber reinforced repairs," Cement and Concrete Research, vol. 63, pp. 117-126, 2014.

[40] C. Zanotti and N. Randl, "Are concrete-concrete bond tests comparable?" Cement and Concrete Composites, vol. 99, pp. 80-88, 2019.
[41] H. Beushausen, B. Höhlig, and M. Talotti, "The influence of substrate moisture preparation on bond strength of concrete overlays and the microstructure of the OTZ," Cement and Concrete Research, vol. 92, pp. 84-91, 2017.

[42] I. Rocha Segundo, L. Silva, C. Palha, F. Elisabete, and S. Hugo, "Surface rehabilitation of Portland cement concrete (PCC) pavements using single or double surface dressings with soft bitumen, conventional or modified emulsions," Construction and Building Materials, vol. 281, 2021.

[43] D. C. Feng, W.-J. Wang, S. Mangalathu, H. Gang, and W. Tao, "Implementing ensemble learning methods to predict the shear strength of RC deep beams with/without web reinforcements," Engineering Structures, vol. 235, 2021.

[44] Y. H. Weng, K. Qian, F. Fu, and F. Qin, "Numerical investigation on load redistribution capacity of flat slab substructures to resist progressive collapse," Journal of Building Engineering, vol. 29, 2020.

[45] Gb175-2007, Common portland Cement, China Architecture \& Building Press, Beijing, China, 2007.

[46] Gb/T. 14685-2011, Pebble and Crushed Stone for Construction, Standards Press of China, Beijing, China, 2011.

[47] Jgj 55-2011, Specification for Mix Proportion Fesign of Ordinary concrete, China Architecture \& Building Press, Beijing, China, 2011.

[48] Cese 38-2004, Technical Specification for Fiber Reinforced concrete Structure, China Architecture \& Building Press, Beijing, China, 2004.

[49] Gb/T50081-2002, Standard for Test Method of Mechanical Properties on Ordinary concrete, China Architecture \& Building Press, Beijing, China, 2002.

[50] A. D. Espeche and J. León, "Estimation of bond strength envelopes for old-to-new concrete interfaces based on a cylinder splitting test," Construction and Building Materials, vol. 25, no. 3, pp. 1222-1235, 2011.

[51] H. Huang, B. Liu, K. Xi, and W. Tao, "Interfacial tensile bond behavior of permeable polymer mortar to concrete," Construction and Building Materials, vol. 121, pp. 210-221, 2016.

[52] B. A. Tayeh, B. H. A. Bakar, M. A. M. Johari, and L. V. Yen, "Evaluation of bond strength between normal concrete substrate and ultra high performance fiber concrete as a repair material," Procedia Engineering, vol. 54, pp. 554-563, 2013.

[53] G. Zhenhai, Principles of Reinforced Concrete, G. Zhenhai, Ed., Vol. 448, Tsinghua University Press, Beijing, China, 2013.

[54] Z. Zhou, Ensemble Methods: Foundations and Algorithms, Chapman and Hell/CRC, Boca Raton, FL, USA, 2012.

[55] Z. Zhou, "Ensemble learing," Encyclopedia Biometr, Vol. 411, Springer, Berlin, Germany, 2015.

[56] A. Lahouar and J. Ben Hadj Slama, "Hour-ahead wind power forecast based on random forests," Renewable Energy, vol. 109, pp. 529-541, 2017.

[57] J. Ma and J. C. P. Cheng, "Identifying the influential features on the regional energy use intensity of residential buildings based on Random Forests," Applied Energy, vol. 183, pp. 193-201, 2016.

[58] Z. Wang, Y. Wang, R. Zeng, S. S. Ravi, and A. Sherry, "Random Forest based hourly building energy prediction," Energy and Buildings, vol. 171, pp. 11-25, 2018.

[59] M. Ormellese, S. Beretta, F. Brugnetti, and B. Andrea, "Effects of non-stationary stray current on carbon steel buried pipelines under cathodic protection," Construction and Building Materials, vol. 281, 2021. 